\title{
USO DE TRAÇADORES NATURAIS E FLUORESCENTES PARA IDENTIFICAÇÃO DE SEÇÕES DE DESCARGA NA BACIA DE JUATUBA
}

\author{
USE OF NATURAL AND FLUORESCENT TRACERS \\ TO IDENTIFY DISCHARGE SECTIONS AT JUATUBA BASIN
}

Vinícius Verna Magalhães Ferreira ${ }^{1}$; Cláudio José Chagas²; Zildete Rocha³; Rubens Martins Moreira ${ }^{4}$; Talita Oliveira Santos ${ }^{5}$; Raquel Luiza Mageste Fonseca ${ }^{6}$; Nayron Cosme Lemos $^{7}$; Elenísio Santana Fonseca ${ }^{8}$; Thais Ferraz ${ }^{9}$; Maria Angela Barros Correa Menezes ${ }^{10}$

Artigo recebido em: 14/01/2016 e aceito para publicação em: 14/04/2016.

DOI: http://dx.doi.org/10.14295/ras.v30i1.28516

\begin{abstract}
Resumo: A Bacia de Juatuba, situada a cerca de $60 \mathrm{~km}$ de Belo Horizonte, tem sido utilizada como um laboratório de diversos estudos hidrossedimentológicos há diversos anos, em projetos de pesquisas que muitas vezes envolvem o uso de traçadores naturais, fluorescentes e radioativos. Neste trabalho, o radônio foi utilizado como traçador para investigar a ocorrência de seções de descarga na Bacia de Juatuba. Para análises das concentrações de atividade do radônio nas amostras de águas coletadas foi utilizado o equipamento RAD 7. Foram encontradas seções com concentrações de atividade de radônio muito acima da média do córrego em estudo. Variações de vazões obtidas com o uso de traçadores fluorescentes e um fluorímetro ratificam o indicativo da existência de seções de descarga no local.
\end{abstract}

Palavras-chave: Traçadores. Descargas subterrâneas. Radônio. Vazões.

\begin{abstract}
The Juatuba Basin, located at about $60 \mathrm{~km}$ from Belo Horizonte, has been used for several years, as a laboratory of several hydrossedimentological studies, in research projects that many times involve the use of natural, fluorescent and radioactive tracers. In this work, radon was used as a natural tracer to investigate the occurrence of discharge sections at Juatuba Basin. To analyze the radon activity concentration of water samples, the equipment RAD 7 was used. It was found sections with radon activity concentrations higher than the average of the stream under study. Flow rate variations obtained with the use of fluorescent tracers and a fluorometer confirm the indicative of the existence of the discharge sections at the site.
\end{abstract}

Keywords: Tracers. Underground discharges. Radon. Flows.

\section{INTRODUÇÃO}

Um traçador é qualquer substância ou partícula (química ou biológica) que pode ser usada para seguir, de forma pontual ou contínua, o comportamento de um determinado sistema ou componente. Um traçador deve possuir as seguintes características: ser atóxico, barato, apresentar detecção inequívoca e quantificação em concentrações mínimas.
Além disso, deve mover-se com a água, não perturbar o sistema em estudo, ser quimicamente estável e não ser absorvido ou filtrado pelo meio sólido através do qual a água se move (DAVIS, 1980).

Diferentes tipos de traçadores têm sido utilizados como ferramentas úteis em estudos hidrossedimentológicos, fornecendo respostas sobre contaminação de meios hídricos, transporte de poluentes, interconexões

\footnotetext{
1,3,4, 6, 7, 89 CDTN - Centro de Desenvolvimento da Tecnologia Nuclear (vvmf@cdtn.br; rochaz@cdtn.br; rubens@cdtn.br)

${ }^{2,10}$ CDTN - Centro de Desenvolvimento da Tecnologia Nuclear. UFMG - Universidade Federal de Minas Gerais (cjc@cdtn.br; menezes@cdtn.br)

5 UFMG - Universidade Federal de Minas Gerais (talitaolsantos@yahoo.com.br)
} 
hidráulicas e dinâmica de sedimentos, entre outros. Como exemplo, Goldscheider et al., (2008), utilizaram um traçador fluorescente (uranina) para pesquisas em regiões cársticas na Suíça, investigando questões hidrológicas e espeleológicas. Bandeira et al., (2012), utilizaram um traçador radioativo (tecnécio 99) para estudos ambientais associados ao impacto ambiental decorrente das descargas de fundo na Pequena Central Hidrelétrica de Paciência, em Minas Gerais, próximo a Juiz de Fora. Clason et al., (2015), investigaram problemas ambientais com o auxílio de traçadores fluorescentes em regiões glaciais na Suécia, enquanto Bekele et al., (2014), utilizaram traçadores químicos para estudar o tempo de residência de águas recicladas em aquíferos na Austrália.

Dentre os traçadores utilizados em vários tipos de pesquisa, os estudos da dinâmica da água podem ser efetuados com o auxílio de espécies isotópicas desta molécula. Neste cenário, a utilização do radônio como traçador merece destaque. Este elemento possui dois isótopos aplicáveis ao estudo de águas subterrâneas: o ${ }^{222} \mathrm{Rn}$ (meia vida de 3,8 dias) produzido pelo decaimento alfa do ${ }^{226} \mathrm{Ra}$ na série do ${ }^{238} \mathrm{U}$, e o ${ }^{220} \mathrm{Rn}$ (meia vida de 56 segundos) produzido pelo decaimento alfa do ${ }^{224} \mathrm{Ra}$ na série do ${ }^{232} \mathrm{Th}$. Por apresentar maior tempo de meia vida, o ${ }^{222} \mathrm{Rn}$ é o isótopo amplamente utilizado como traçador de águas subterrâneas e superficiais. O radônio é enriquecido em águas subterrâneas quando comparado a águas de superfície, devido ao fato da água subterrânea estar em contato com grãos minerais que contêm rádio, e da água de superfície estar sujeita à turbulência promovida por fatores ambientais, o que permite sua fuga (BURNETT et al., 2008). Além disso esse elemento é quimicamente inerte, o que possibilita a desconsideração de reações biogeoquímicas e facilita a sua medição.
Vários trabalhos já realizados utilizaram o ${ }^{222} \mathrm{Rn}$ como traçador em estudos hidrológicos, entre os quais:

- Chanyotha et al., (2014), para identificação de seções de descarga na Tailândia e balanço de massa nos trechos em estudo;

- Dimova et al., (2013), para investigar seções de descarga em sete lagos rasos na Flórida por 2 anos;

- Erõss et al., (2012), para caracterizar as águas de regiões cársticas na Hungria, enquanto Savoy et al., (2011), fizeram o mesmo para aquíferos cársticos na Suíça;

- Santos e Eyre (2011), para estudar a interação entre águas subterrâneas e superficiais na Austrália, enquanto Schubert e Paschke (2015), para estudos hidrológicos e hidrogeológicos na Alemanha;

- Dugan et al., (2011), para identificar zonas de descarga em lagos no Ártico, enquanto Close et al., (2014), para estudos dentro da mesma temática na Nova Zelândia.

O objetivo deste trabalho é o de identificar seções de descarga de águas subterrâneas utilizando o radônio como traçador natural na Bacia de Juatuba. A quantificação desta descarga será estimada com o auxílio de traçadores fluorescentes.

\section{2 ÁREA DE ESTUDO}

A Bacia de Juatuba (Figura 1) está inserida no Alto Rio São Francisco, tendo uma área de $442 \mathrm{~km}^{2}$ a cerca de $60 \mathrm{~km}$ de Belo Horizonte, abrangendo os municípios de Mateus Leme, Igarapé e Itaúna. Os principais cursos hídricos que formam o Rio Juatuba são os Ribeirões Serra Azul e Mateus Leme, que possuem uma área de drenagem de 265 e $155 \mathrm{~km}^{2}$ respectivamente. Segundo a classificação de Köeppen o clima na área de estudo é do tipo Aw, caracterizado por um verão tropical com temperaturas médias mensais acima de $18^{\circ} \mathrm{C}$, e por uma estação hibernal seca de 4 a 6 meses (DRUMOND, 2004). 




Figura 1 - Localização da Bacia de Juatuba

Figure 1 - Location of the Juatuba Basin

De acordo com estudos hidrogeológicos já feitos no local "a principal contribuição subterrânea aos elementos e drenagem provém da circulação subsuperficial em meios com porosidade desenvolvida no manto de alteração de rochas graníticas, básicas, xistosas e metassedimentares; nos depósitos de cobertura argilo-arenosas terciárias de talus e aluviões, cujos freáticos não ultrapassam 5 metros de profundidade. A renovação dessa água se procede substancialmente de ano para ano, sob regime pluviométrico de 1000 $\mathrm{mm}$, o que assegura substancial recarga dos aquíferos, bem como a perenidade dos rios que drenam a região estudada" (CETEC, 1983). Estima-se que as recargas dos aquíferos na bacia girem em torno de $37 \%$ do total de chuva precipitado (DRUMOND, 2004).

Observa-se aqui que a Bacia de Juatuba foi, nos últimos anos, cenário de diversos projetos de pesquisa, entre os quais:

- Aplicação da Técnica de Traçadores ao Es- tudo de Hidrogramas de Cheias na Bacia Representativa de Juatuba - MG (FAPEMIG TEC-2098/96);

- Determinação das Taxas de Infiltração e Evapotranspiração na Bacia Representativa de Juatuba - MG, através da Técnica de Traçadores (FAPEMIG CRA-2509/98);

- Estudo da Formação de Escoamentos Utilizando Traçadores Naturais na Bacia Representativa de Juatuba - Alto São Francisco (FINEP 01.06.0109.00);

- Núcleo de Estudos Experimentais em Bacias Hidrográficas (FAPEMIG ESTR-110/9242);

- Estudos Hidrossedimentológicos na subbacia do Córrego Mato Frio - Bacia Representativa de Juatuba (CNPq 477159/2012-5).

Já em 2013 a FAPEMIG - Fundação de Amparo a Pesquisa do Estado de Minas Gerais aprovou o projeto intitulado "Aplicação da técnica de traçadores para estudos da inter relação entre as águas subterrâneas e superficiais na Bacia de Juatuba", no escopo 
do qual foi realizado o trabalho aqui apresentado.

Observa-se aqui que estudos anteriores efetuados no primeiro ano do projeto foram capazes de identificar duas possíveis seções de descarga (Figura 2) no Córrego do
Fundão (situado nas coordenadas $23 \mathrm{~K}$ 552957.58 E / 7778762.24 S), tendo em vista terem sido encontrados trechos com concentrações de radônio 222 bastante elevadas (FERREIRA et al., 2015).

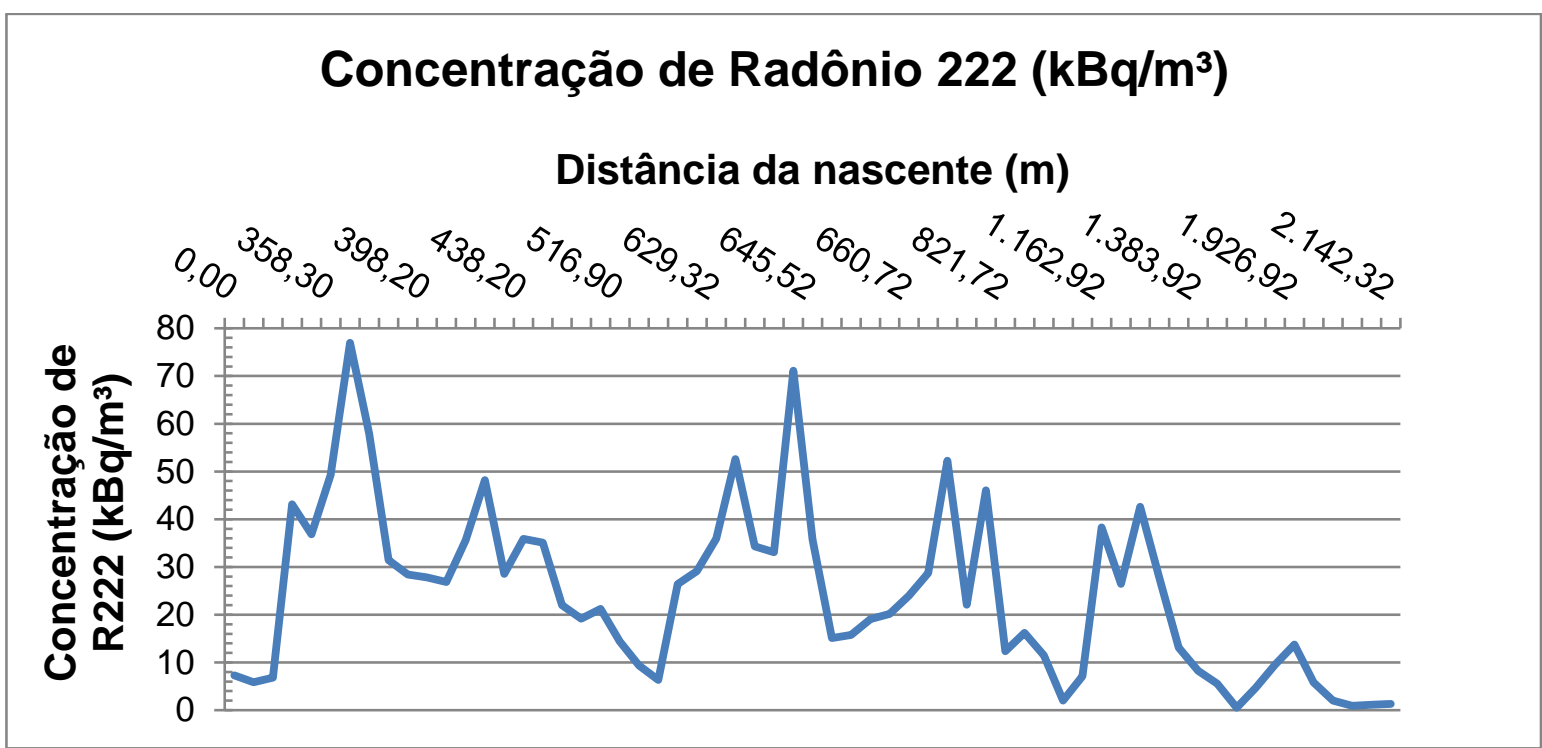

Figura 2 - Concentração de radônio 222 a partir da nascente do Córrego do Fundão. Os picos de concentração correspondem aos locais nos quais há descarga das águas subterrâneas nas águas superficiais

Figure 2 - Radon concentration from the source of the Fundão stream. The concentration peaks correspond to the places where there are discharges of groundwater into surface waters

\section{METODOLOGIA}

Em duas seções em estudo no Córrego do Fundão (as mesmas estudadas em etapas anteriores do projeto) foram realizadas em 2015 duas campanhas para coleta de água com espaçamento de cerca de 5 metros entre as mesmas, ao longo de todo o trecho, nos meses de fevereiro e julho. Uma terceira campanha foi feita no mês de setembro, em uma outra seção mais a jusante, na qual também o radônio 222 foi previamente encontra- do. Ressalta-se aqui que todos os experimentos foram realizados em períodos sem chuva.

A água do córrego foi coletada com o auxílio de uma bomba peristáltica alimentada por uma bateria 12 volts, bem próxima ao leito do mesmo, até que frascos de vidro âmbar com capacidade de $275 \mathrm{ml}$ fossem preenchidos. Após sua devida identificação, as amostras de água foram analisadas pelo equipamento RAD 7 (Figura 3), que efetua medidas da concentração de radônio em águas. 


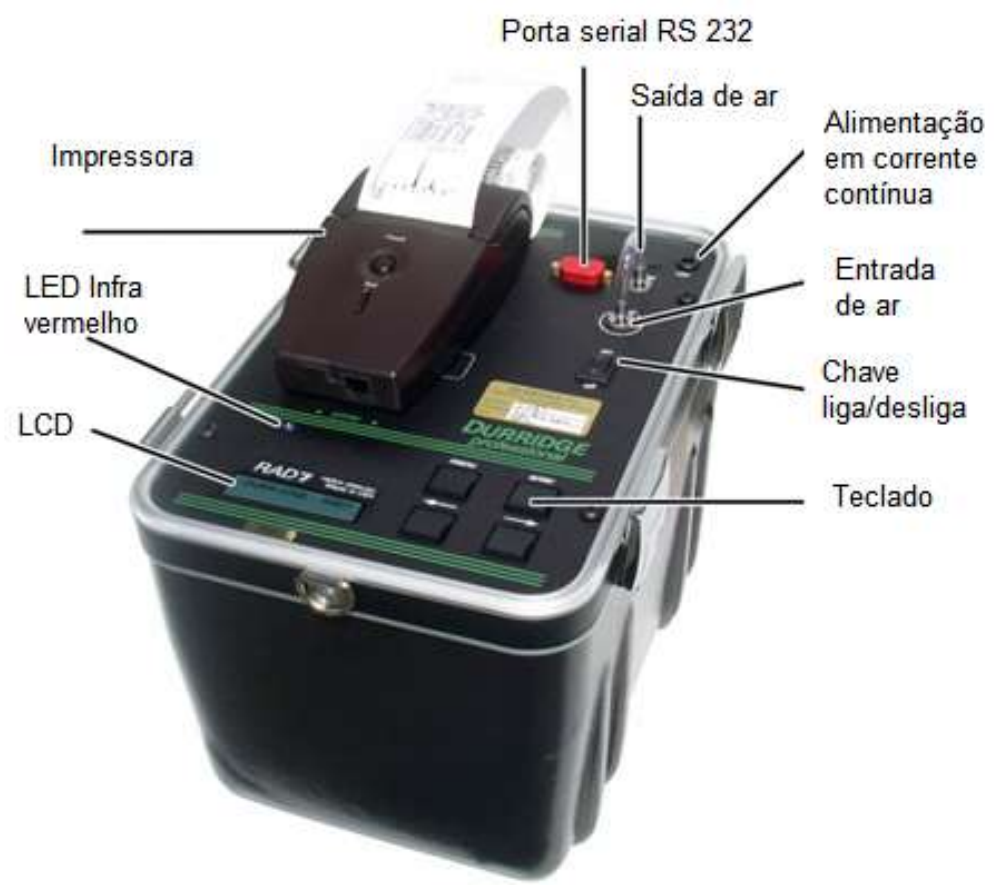

Figura 3 - Equipamento RAD 7 (DURRIDGE, 2015)

Figure 3 - AD 7 device (DURRIDGE, 2015)

Durante o funcionamento do RAD7, um fluxo constante de água passa através de um permutador água/ar que distribui o radônio presente na água corrente para um circuito formado pelo sistema de secagem e um monitor contínuo.

O RAD7 apresenta duas formas de se medir radônio em águas: modo GRAB para medidas pontuais e modo SCAN (varredura), no qual são feitas medidas contínuas. De acordo com o cenário a ser estudado, foi utilizado o modo GRAB, para que as seções de descarga ao longo do córrego pudessem ser encontradas.

No modo GRAD, o aparelho trabalha com 3 circuitos, sendo eles:

1. Secagem - o aparelho trabalha para retirar a água presente no sistema, de forma que a mesma não o danifique. Nesta etapa a umidade interna do aparelho deve ser $\leq 6 \%$ para que a leitura das amostras possa ser realizada;

2. Análise - durante 20 minutos o aparelho realiza 4 leituras (de 5 minutos cada) e apresenta também o desvio padrão de cada uma. Ao final, o aparelho calcula os valores médios associados à amostra em questão;
3. Limpeza - após a leitura de uma amostra o aparelho necessita ser limpo, num circuito aberto para eliminar o radônio que se encontra no sistema, visando não alterar as próximas leituras.

Considerando o equilíbrio secular, para casos onde a constante de decaimento $\lambda$ de um elemento é muito maior que do outro, para o caso do ${ }^{222} \mathrm{Rn}$ e do ${ }^{226} \mathrm{Ra}$ a equação que rege este processo é apresentada abaixo:

$$
\mathrm{A}_{\mathrm{Rn}}(\mathrm{t})=\mathrm{A}_{0 \mathrm{Ra}} \quad\left(1-\mathrm{e}^{-} \lambda^{\mathrm{t}}\right)
$$

sendo $A_{R n}(t)$ a concentração medida de ${ }^{222} \mathrm{Rn}$ no tempo t, A0Ra a concentração inicial (constante) de ${ }^{226} \mathrm{Ra}$ na amostra e $\lambda$ a constante de decaimento do ${ }^{222} \mathrm{Rn}$.

No caso da representação da concentração de atividade para amostras de água medidas neste trabalho, deve ser levado em consideração também que no momento inicial existe uma concentração de radônio advinda do solo e já presente na amostra, que decai naturalmente. Assim, a Equação 2 mostra a concentração de radônio em função da concentração inicial de ${ }^{222} \mathrm{Rn}$ e ${ }^{226} \mathrm{Ra}$. 
$A_{R n}(t)=A_{0 R a}\left(1-e^{-\lambda t}\right)+A_{0 R n}\left(e^{-\lambda t}\right)$

sendo que $\mathrm{A}_{0 \mathrm{Rn}}$ equivale à concentração inicial de ${ }^{222} \mathrm{Rn}$ na amostra.

Observa-se que a primeira parcela da equação se refere à geração de ${ }^{222} \mathrm{Rn}$ pelo decaimento do ${ }^{226} \mathrm{Ra}$ na amostra, e a segunda parcela se refere ao ${ }^{222} \mathrm{Rn}$ que existe na amostra devido à difusão do gás do solo para a água (CORREA, 2011).

Nos trechos onde foram realizadas as medições de radônio, também se mediu a vazão do curso de água. As variações esperadas de vazão nos trechos em estudo devem corresponder à descarga no local. Desta forma, é possível verificar a existência da correlação existente entre a descarga (por meio das medidas de radônio) e a vazão. As medidas de vazões foram feitas com o uso de traçadores fluorescentes e de um fluorímetro. Traçadores fluorescentes como rodamina e fluoresceína são bastante adequados a estudos hidrossedimentológicos. Isto ocorre pelo fato destes não serem adsorvidos pelos sedimentos em suspensão, pelo material sólido e

pela vegetação presente no leito dos cursos de água ou nas suas margens. Além disso, esses traçadores são altamente solúveis, facilmente detectáveis e muito pouco degradáveis.

A injeção de traçadores fluorescentes possibilita, além da obtenção da curva de passagem que fornece informações sobre a dispersão e a advecção da pluma formada, o cálculo da vazão líquida (Equação 3):

Q

sendo $\mathrm{Q}$ a vazão líquida ( $\left.\mathrm{m}^{3} / \mathrm{segundo}\right), \mathrm{M}$ a massa de traçador injetada, $\mathrm{C}$ a concentração do traçador na água e t o tempo.

A expressão no denominador da Equação 3 representa a área da curva de passagem sem normalização (BANDEIRA, 2004). O fluorímetro utilizado durante a execução destes experimentos foi o GGUN FL30 (Figura 4).

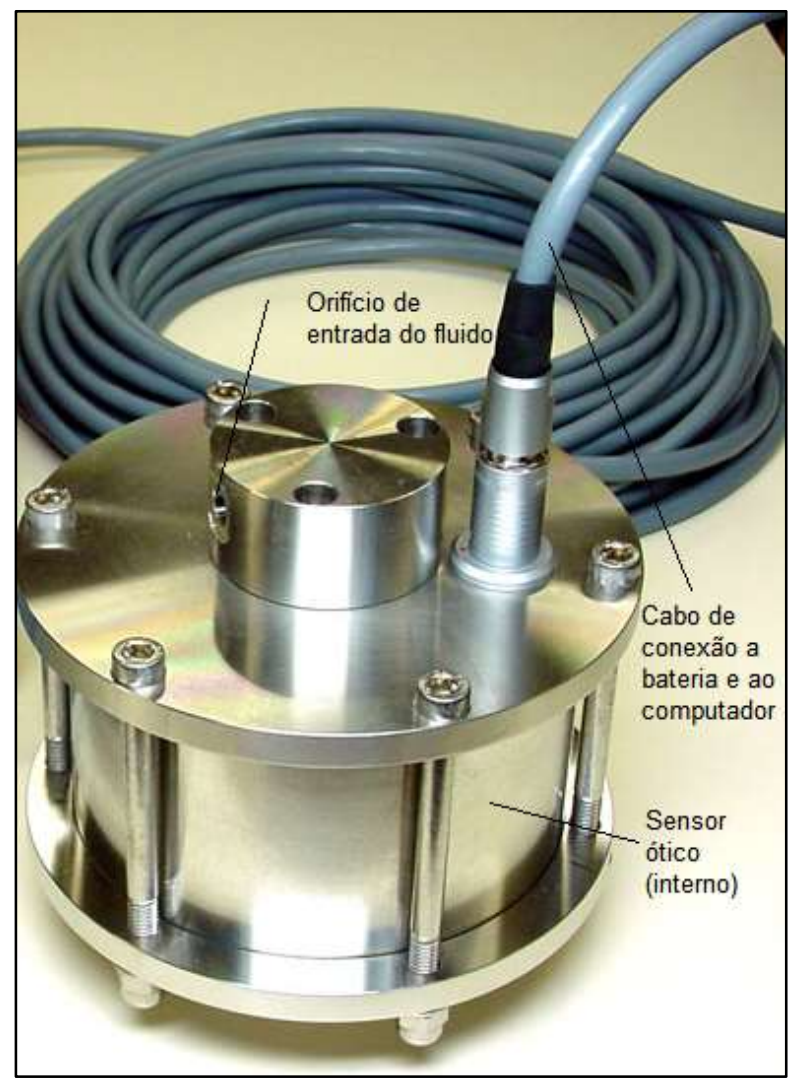

Figura 4 - Fluorímetro GGUN FL 30

Figure 4 - GGUN FL 30 Fluorometer 


\section{RESULTADOS E DISCUSSÕES}

As Tabelas 1 e 2 apresentam os resultados referentes a campanha feita em fevereiro de 2015. Verifica-se que as concentrações de radônio 222 variaram entre 19 e 57
$\mathrm{KBq} / \mathrm{m}^{3}$ (Tabela 1), e 15 e $71 \mathrm{KBq} / \mathrm{m}^{3}$ (Tabela 2), sendo que nos experimentos de 2014, feitos em também em outras seções do Córrego, foram encontrados valores bem inferiores.

Tabela 1 - Concentrações de ${ }^{222} \mathrm{Rn}$ nos pontos da $1^{\mathrm{a}}$ campanha - seção 1

Table 1 - Concentrations of ${ }^{222} \mathrm{Rn}$ at the first campaign points - section 1

\begin{tabular}{|c|c|c|c|c|c|}
\hline Ponto & $\begin{array}{c}\text { Concentração } \\
\text { de radônio } \\
\text { medida } \\
\left(\mathbf{k B q} / \mathbf{m}^{3}\right)\end{array}$ & $\begin{array}{c}\text { Data e } \\
\text { hora da } \\
\text { coleta }\end{array}$ & $\begin{array}{c}\text { Data e } \\
\text { hora da } \\
\text { leitura }\end{array}$ & $\begin{array}{c}\text { Tempo decor- } \\
\text { rido } \\
\text { entre a } \\
\text { coleta e } \\
\text { leitura (dias) }\end{array}$ & $\begin{array}{c}\text { Concentração } \\
\text { de radônio } \\
\text { corrigida } \\
\left(\mathbf{k B q} / \mathbf{m}^{3}\right)\end{array}$ \\
\hline $1 A^{*}$ & $25,92 \pm 0,95$ & $\begin{array}{c}11 / 2 / 2015 \\
10: 30\end{array}$ & $\begin{array}{c}13 / 2 / 2015 \\
09: 23\end{array}$ & 1,9535 & $36,84 \pm 1,35$ \\
\hline $1 \mathrm{~B} * *$ & $34,50 \pm 2,24$ & $\begin{array}{c}11 / 2 / 2015 \\
10: 40\end{array}$ & $\begin{array}{c}13 / 2 / 2015 \\
10: 10\end{array}$ & 1,9792 & $49,27 \pm 3,20$ \\
\hline $2 * *$ & $40,35 \pm 0,63$ & $\begin{array}{c}11 / 2 / 2015 \\
10: 50\end{array}$ & $\begin{array}{c}13 / 2 / 2015 \\
10: 55\end{array}$ & 2,0035 & $57,88 \pm 0,90$ \\
\hline $3 * *$ & $21,85 \pm 2,93$ & $\begin{array}{c}11 / 2 / 2015 \\
11: 15\end{array}$ & $\begin{array}{c}13 / 2 / 2015 \\
11: 45\end{array}$ & 2,0208 & $31,44 \pm 4,22$ \\
\hline $4 * *$ & $19,65 \pm 2,19$ & $\begin{array}{c}11 / 2 / 2015 \\
11: 30\end{array}$ & $\begin{array}{c}13 / 2 / 2015 \\
12: 45\end{array}$ & 2,0521 & $28,43 \pm 3,17$ \\
\hline $5 * *$ & $19,12 \pm 1,68$ & $\begin{array}{c}11 / 2 / 2015 \\
11: 45\end{array}$ & $\begin{array}{c}13 / 2 / 2015 \\
13: 45\end{array}$ & 2,0833 & $27,82 \pm 2,44$ \\
\hline $6^{* *}$ & $18,37 \pm 1,91$ & $\begin{array}{c}11 / 2 / 2015 \\
11: 55\end{array}$ & $\begin{array}{c}13 / 2 / 2015 \\
14: 30\end{array}$ & 2,1076 & $26,85 \pm 2,79$ \\
\hline $7 * *$ & $24,27 \pm 1,01$ & $\begin{array}{c}11 / 2 / 2015 \\
12: 10\end{array}$ & $\begin{array}{c}13 / 2 / 2015 \\
15: 15\end{array}$ & 2,1285 & $35,60 \pm 1,48$ \\
\hline $8 * *$ & $19,37 \pm 0,76$ & $\begin{array}{c}11 / 2 / 2015 \\
12: 20\end{array}$ & $\begin{array}{c}13 / 2 / 2015 \\
16: 05\end{array}$ & 2,1563 & $28,56 \pm 1,12$ \\
\hline $9 * *$ & $24,22 \pm 2,07$ & $\begin{array}{c}11 / 2 / 2015 \\
12: 30\end{array}$ & $\begin{array}{c}13 / 2 / 2015 \\
16: 50\end{array}$ & 2,1806 & $35,87 \pm 3,07$ \\
\hline $10 * *$ & $14,77 \pm 2,13$ & $\begin{array}{c}11 / 2 / 2015 \\
12: 43\end{array}$ & $\begin{array}{c}13 / 2 / 2015 \\
17: 45\end{array}$ & 2,2097 & $21,99 \pm 3,17$ \\
\hline $11 * *$ & $12,8 \pm 0,93$ & $\begin{array}{c}11 / 2 / 2015 \\
12: 50\end{array}$ & $\begin{array}{c}13 / 2 / 2015 \\
18: 30\end{array}$ & 2,2361 & $19,14 \pm 1,39$ \\
\hline $12 * *$ & $14,12 \pm 0,54$ & $\begin{array}{c}11 / 2 / 2015 \\
13: 05\end{array}$ & $\begin{array}{c}13 / 2 / 2015 \\
19: 25\end{array}$ & 2,2639 & $21,22 \pm 0,81$ \\
\hline
\end{tabular}

\footnotetext{
* - coleta com seringa hipodérmica;
}

** - coleta com bomba peristáltica. 
Tabela 2 - Concentrações de ${ }^{222} \mathrm{Rn}$ nos pontos da $1^{\mathrm{a}}$ campanha - seção 2

Table 2 - Concentrations of ${ }^{222} \mathrm{Rn}$ at the first campaign points - section 2

\begin{tabular}{|c|c|c|c|c|c|}
\hline Ponto & $\begin{array}{c}\text { Concentração } \\
\text { de radônio } \\
\text { medida } \\
\left(\mathbf{k B q} / \mathbf{m}^{3}\right)\end{array}$ & $\begin{array}{c}\text { Data e } \\
\text { hora da } \\
\text { coleta }\end{array}$ & $\begin{array}{c}\text { Data e } \\
\text { hora da } \\
\text { leitura }\end{array}$ & $\begin{array}{c}\text { Tempo decorri- } \\
\text { do } \\
\text { entre a } \\
\text { coleta e } \\
\text { leitura (dias) }\end{array}$ & $\begin{array}{c}\text { Concentração } \\
\text { de radônio } \\
\text { corrigida }\left(\mathbf{k B q} / \mathbf{m}^{\mathbf{3}}\right)\end{array}$ \\
\hline $1 \mathrm{~A}$ & $28,42 \pm 1,78$ & $\begin{array}{c}10 / 2 / 2015 \\
14: 35\end{array}$ & $\begin{array}{c}10 / 2 / 2015 \\
17: 50\end{array}$ & 0,1354 & $29,12+1,82$ \\
\hline $1 \mathrm{~B}$ & $34,87 \pm 3,56$ & $\begin{array}{c}10 / 2 / 2015 \\
14: 40\end{array}$ & $\begin{array}{c}10 / 2 / 2015 \\
18: 35\end{array}$ & 0,1632 & $35,91 \pm 3,67$ \\
\hline $2 \mathrm{~A}$ & $33,22 \pm 1,79$ & $\begin{array}{c}10 / 2 / 2015 \\
15: 00\end{array}$ & $\begin{array}{c}10 / 2 / 2015 \\
19: 15\end{array}$ & 0,1771 & $34,30 \pm 1,85$ \\
\hline $2 B$ & $50,22 \pm 4,69$ & $\begin{array}{c}10 / 2 / 2015 \\
14: 55\end{array}$ & $\begin{array}{c}10 / 2 / 2015 \\
21: 07\end{array}$ & 0,2583 & $52,61 \pm 4,91$ \\
\hline $3 \mathrm{~A}$ & $67,52 \pm 4,83$ & $\begin{array}{c}10 / 2 / 2015 \\
15: 06\end{array}$ & $\begin{array}{c}10 / 2 / 2015 \\
22: 00\end{array}$ & 0,2875 & $71,11 \pm 5,09$ \\
\hline $3 B$ & $26,07 \pm 1,75$ & $\begin{array}{c}10 / 2 / 2015 \\
15: 10\end{array}$ & $\begin{array}{c}12 / 2 / 2015 \\
09: 17\end{array}$ & 1,7549 & $35,78 \pm 2,40$ \\
\hline $4 \mathrm{~A}$ & $10,85 \pm 0,34$ & $\begin{array}{c}10 / 2 / 2015 \\
15: 20\end{array}$ & $\begin{array}{c}12 / 2 / 2015 \\
11: 15\end{array}$ & 1,8299 & $15,08 \pm 0,47$ \\
\hline $4 B$ & $11,22 \pm 0,73$ & $\begin{array}{c}10 / 2 / 2015 \\
15: 30\end{array}$ & $\begin{array}{c}12 / 2 / 2015 \\
12: 45\end{array}$ & 1,8854 & $15,75 \pm 1,03$ \\
\hline $5 \mathrm{~A}$ & $13,22 \pm 4,58$ & $\begin{array}{c}10 / 2 / 2015 \\
15: 44\end{array}$ & $\begin{array}{c}12 / 2 / 2015 \\
16: 45\end{array}$ & 2,0424 & $19,10 \pm 6,62$ \\
\hline $5 \mathrm{~B}$ & $13,87 \pm 0,88$ & $\begin{array}{c}10 / 2 / 2015 \\
15: 45\end{array}$ & $\begin{array}{c}12 / 2 / 2015 \\
17: 43\end{array}$ & 2,0819 & $20,18 \pm 1,28$ \\
\hline $6 \mathrm{~A}$ & $16,45 \pm 1,27$ & $\begin{array}{c}10 / 2 / 2015 \\
15: 50\end{array}$ & $\begin{array}{c}12 / 2 / 2015 \\
18: 20\end{array}$ & 2,1042 & $24,03 \pm 1,85$ \\
\hline $6 \mathrm{~B}$ & $19,52 \pm 0,53$ & $\begin{array}{c}10 / 2 / 2015 \\
15: 55\end{array}$ & $\begin{array}{c}12 / 2 / 2015 \\
19: 25\end{array}$ & 2,1458 & $28,73 \pm 0,78$ \\
\hline
\end{tabular}

Obs. - foram realizadas duas coletas em cada ponto, todas com bomba peristáltica

Os experimentos realizados em fevereiro/2015 com o fluorímetro GGUN para medidas de vazão não tiveram resultados satisfatórios devido a uma série de fatores:

- a movimentação da equipe no leito do córrego para a coleta de água aumentou sobremaneira a turbidez do meio. Esse fato comprometeu a eficiência do fluorímetro, pois a turbidez acaba se comportando como outra pluma em movimento, em paralelo a pluma do traçador. Desta forma, nas campanhas seguintes as tarefas de medição de vazão e coleta de água foram realizadas simultaneamente, mas em seções diferentes;
- a injeção foi realizada em um ponto não muito distante do GGUN, todavia o tempo de residência da nuvem de traçador foi muito longo. Como os dados estavam sendo armazenados em um notebook, a bateria do mesmo acabou antes que houvesse a passagem da maior fração do traçador. Nas campanhas seguintes a injeção foi realizada em pontos mais próximos ao local onde a mesma foi detectada, de modo a assegurar que a leitura dos dados pudesse ser realizada integralmente pelo computador;

- como nesta campanha apenas haviam sido preparadas soluções de rodamina, não foi possível efetuar outro lançamento em um 
local mais próximo a detecção, pois haveria a mistura da $1^{\mathrm{a}}$ com a $2^{\mathrm{a}}$ injeção (devido à questão do longo tempo de residência). Para as campanhas seguintes foram levadas a campo soluções de rodamina e fluoresceína, para possibilitar um segundo lançamento (no mesmo ponto) caso ocorressem problemas na $1^{\mathrm{a}}$ injeção.

As Tabelas 3 e 4 apresentam resultados das concentrações de radônio 222 referentes à campanha feita em julho de 2015. Observa-se que os valores variaram entre 12 e $57 \mathrm{KBq} / \mathrm{m}^{3}$ (Tabela 3) e 10 e $53 \mathrm{KBq} / \mathrm{m}^{3}$ (Tabela 4). As Figuras 5 a 8 apresentam os resultados das medidas de vazão nas duas seções em estudo. O programa que processa os dados de vazão - FLUO, integra os acessórios adquiridos com o fluorímetro. Tendo em vista a presença de radônio 222 em concentrações superiores àquelas encontradas em outros trechos do Córrego do Fundão, o aumento de vazão nas duas seções pode ser explicado pela existência de descargas subterrâneas local

Tabela 3 - Concentrações de ${ }^{222} \mathrm{Rn}$ nos pontos da $2^{\mathrm{a}}$ campanha - seção 1

Table 3 - Concentrations of ${ }^{222} \mathrm{Rn}$ at the second campaign points - section 1

\begin{tabular}{|c|c|c|c|c|c|}
\hline Ponto & $\begin{array}{c}\text { Concentração } \\
\text { de radônio } \\
\text { medida } \\
\left(\mathrm{kBq} / \mathrm{m}^{3}\right)\end{array}$ & $\begin{array}{c}\text { Data e } \\
\text { hora da } \\
\text { coleta }\end{array}$ & $\begin{array}{c}\text { Data e } \\
\text { hora da } \\
\text { leitura }\end{array}$ & $\begin{array}{c}\text { Tempo decorrido } \\
\text { entre a coleta e } \\
\text { leitura } \\
\text { (dias) }\end{array}$ & $\begin{array}{l}\text { Concentração de } \\
\text { radônio corrigida } \\
\qquad\left(\mathbf{k B q} / \mathbf{m}^{3}\right)\end{array}$ \\
\hline & & $15 / 7 / 15$ & $15 / 7 / 15$ & \multirow{2}{*}{0,9479} & \\
\hline 1 & $17,7+1,67$ & $10: 20$ & $10: 22$ & & $20,99+1,98$ \\
\hline & & $15 / 7 / 15$ & $15 / 7 / 15$ & \multirow{2}{*}{1,8298} & \\
\hline 2 & $12,6 \pm 1,88$ & $10: 31$ & $11: 14$ & & $17,51 \pm 2,61$ \\
\hline 3 & $8,78 \pm 1,52$ & $\begin{array}{c}15 / 7 / 15 \\
10: 00\end{array}$ & $\begin{array}{c}15 / 7 / 15 \\
11: 56\end{array}$ & 1,8555 & $12,26 \pm 2,12$ \\
\hline 4 & $12,1 \pm 1,72$ & $\begin{array}{c}15 / 7 / 15 \\
11: 00\end{array}$ & $\begin{array}{c}15 / 7 / 15 \\
12: 41\end{array}$ & 1,8854 & $16,98 \pm 2,41$ \\
\hline 5 & $12,0 \pm 1,12$ & $\begin{array}{c}15 / 7 / 15 \\
11: 15\end{array}$ & $\begin{array}{c}15 / 7 / 15 \\
13: 14\end{array}$ & 1,9222 & $16,96 \pm 1,58$ \\
\hline 6 & $32,8 \pm 1,91$ & $\begin{array}{c}15 / 7 / 15 \\
11: 40\end{array}$ & $\begin{array}{c}15 / 7 / 15 \\
14: 40\end{array}$ & 1,9465 & $46,56 \pm 2,71$ \\
\hline 7 & $14,3 \pm 1,81$ & $\begin{array}{c}15 / 7 / 15 \\
11: 50\end{array}$ & $\begin{array}{c}15 / 7 / 15 \\
15: 20\end{array}$ & 1,9722 & $20,39 \pm 2,58$ \\
\hline 8 & $19,7 \pm 1,97$ & $\begin{array}{c}15 / 7 / 15 \\
12: 00\end{array}$ & $\begin{array}{c}15 / 7 / 15 \\
16: 07\end{array}$ & 2,0006 & $28,24 \pm 2,82$ \\
\hline 9 & $17,7 \pm 1,61$ & $\begin{array}{c}15 / 7 / 15 \\
12: 20\end{array}$ & $\begin{array}{c}16 / 7 / 15 \\
8: 35\end{array}$ & 2,0236 & $25,47 \pm 2,31$ \\
\hline 10 & $24,6 \pm 0,84$ & $\begin{array}{c}15 / 7 / 15 \\
12: 35\end{array}$ & $\begin{array}{c}16 / 7 / 15 \\
10: 25\end{array}$ & 4,6958 & $57,28 \pm 1,95$ \\
\hline 11 & $10,1 \pm 1,9$ & $\begin{array}{c}15 / 7 / 15 \\
12: 40\end{array}$ & $\begin{array}{c}16 / 7 / 15 \\
11: 15\end{array}$ & 4,7187 & $23,61 \pm 4,44$ \\
\hline 12 & $12,8 \pm 0,6$ & $\begin{array}{c}15 / 07 / 2015 \\
13: 30\end{array}$ & $\begin{array}{c}16 / 7 / 15 \\
12: 05\end{array}$ & 4,7430 & $30,06 \pm 4,46$ \\
\hline 13 & $13,9 \pm 0,6$ & $\begin{array}{c}15 / 7 / 15 \\
16: 20\end{array}$ & $\begin{array}{c}20 / 7 / 15 \\
10: 52\end{array}$ & 4,7222 & $32,81 \pm 1,41$ \\
\hline 14 & $15,7 \pm 0,98$ & $\begin{array}{c}15 / 7 / 15 \\
16: 28\end{array}$ & $\begin{array}{c}20 / 7 / 15 \\
11: 42\end{array}$ & 4,8013 & $37,26 \pm 2,32$ \\
\hline
\end{tabular}

Obs. - todas as coletas foram feitas com bomba peristáltica 
Tabela 4 - Concentrações de ${ }^{222} \mathrm{Rn}$ nos pontos da $2^{\mathrm{a}}$ campanha - seção 2

Table 4 - Concentrations of ${ }^{222} \mathrm{Rn}$ at the second campaign points - section 2

\begin{tabular}{|c|c|c|c|c|c|}
\hline Ponto & $\begin{array}{c}\text { Concentração de } \\
\text { radônio medida } \\
\quad\left(\mathbf{k B q} / \mathbf{m}^{3}\right)\end{array}$ & $\begin{array}{c}\text { Data e } \\
\text { hora da } \\
\text { coleta } \\
\end{array}$ & $\begin{array}{c}\text { Data e } \\
\text { hora da } \\
\text { leitura }\end{array}$ & $\begin{array}{c}\text { Tempo decor- } \\
\text { rido entre a } \\
\text { coleta e leitura } \\
\text { (dias) }\end{array}$ & $\begin{array}{c}\text { Concentração } \\
\text { de radônio } \\
\text { corrigida } \\
\left(\mathbf{k B q} / \mathbf{m}^{3}\right) \\
\end{array}$ \\
\hline \multirow{3}{*}{1} & \multirow{3}{*}{$10,5 \pm 1,13$} & $15 / 7 / 15$ & $15 / 7 / 15$ & \multirow{3}{*}{0,0013} & \multirow{3}{*}{$10,5 \pm 1,13$} \\
\hline & & $10: 20$ & $10: 22$ & & \\
\hline & & $15 / 7 / 15$ & $15 / 7 / 15$ & & \\
\hline \multirow[t]{2}{*}{2} & \multirow{2}{*}{$25,8 \pm 2,03$} & $10: 31$ & $11: 14$ & \multirow[t]{2}{*}{0,0298} & \multirow{2}{*}{$25,93 \pm 2,04$} \\
\hline & & $15 / 7 / 15$ & $15 / 7 / 15$ & & \\
\hline \multirow[t]{2}{*}{3} & \multirow{2}{*}{$12,8 \pm 1,2$} & $10: 45$ & $11: 56$ & \multirow[t]{2}{*}{0,0493} & \multirow[t]{2}{*}{$12,91 \pm 1,21$} \\
\hline & & $15 / 7 / 15$ & $15 / 7 / 15$ & & \\
\hline \multirow[t]{2}{*}{4} & \multirow{2}{*}{$53,7 \pm 2,47$} & 11:00 & $12: 41$ & \multirow[t]{2}{*}{0,0701} & \multirow{2}{*}{$54,38 \pm 2,50$} \\
\hline & & $15 / 7 / 15$ & $15 / 7 / 15$ & & \\
\hline \multirow[t]{2}{*}{5} & \multirow[t]{2}{*}{$51,8 \pm 4,1$} & $11: 15$ & $13: 14$ & \multirow[t]{2}{*}{0,0826} & \multirow[t]{2}{*}{$52,57 \pm 4,16$} \\
\hline & & $15 / 7 / 15$ & $15 / 7 / 15$ & & \\
\hline \multirow[t]{2}{*}{6} & \multirow{2}{*}{$52,5 \pm 1,82$} & $11: 40$ & $14: 40$ & \multirow[t]{2}{*}{0,1250} & \multirow{2}{*}{$53,69 \pm 1,86$} \\
\hline & & $15 / 7 / 15$ & $15 / 7 / 15$ & & \\
\hline \multirow[t]{2}{*}{7} & \multirow{2}{*}{$13,9 \pm 2,08$} & $11: 50$ & $15: 20$ & \multirow[t]{2}{*}{0,1458} & \multirow[t]{2}{*}{$14,27 \pm 2,13$} \\
\hline & & $15 / 7 / 15$ & $15 / 7 / 15$ & & \\
\hline \multirow[t]{2}{*}{8} & \multirow{2}{*}{$40,9 \pm 2,14$} & $12: 00$ & 16:07 & \multirow[t]{2}{*}{0,1715} & \multirow{2}{*}{$42,18 \pm 2,21$} \\
\hline & & $15 / 7 / 15$ & $16 / 7 / 15$ & & \\
\hline \multirow[t]{2}{*}{9} & \multirow{2}{*}{$12,3 \pm 1,62$} & $12: 20$ & $8: 35$ & 0,8437 & $14,31 \pm 1,88$ \\
\hline & & $15 / 7 / 15$ & $16 / 7 / 15$ & & \\
\hline 10 & $14,5 \pm 1,38$ & $12: 35$ & $10: 25$ & 0,9097 & $17,08 \pm 1,62$ \\
\hline & & $15 / 7 / 15$ & $16 / 7 / 15$ & & \\
\hline 11 & $20,8 \pm 1,39$ & $12: 40$ & 11:15 & 0,9409 & $24,64 \pm 1,64$ \\
\hline & & $15 / 07 / 2015$ & $16 / 7 / 15$ & & \\
\hline 12 & $8,51+0,69$ & $13: 30$ & $12: 05$ & 0,9409 & $10,08+0,82$ \\
\hline
\end{tabular}

Obs. - todas as coletas foram feitas com bomba peristáltica

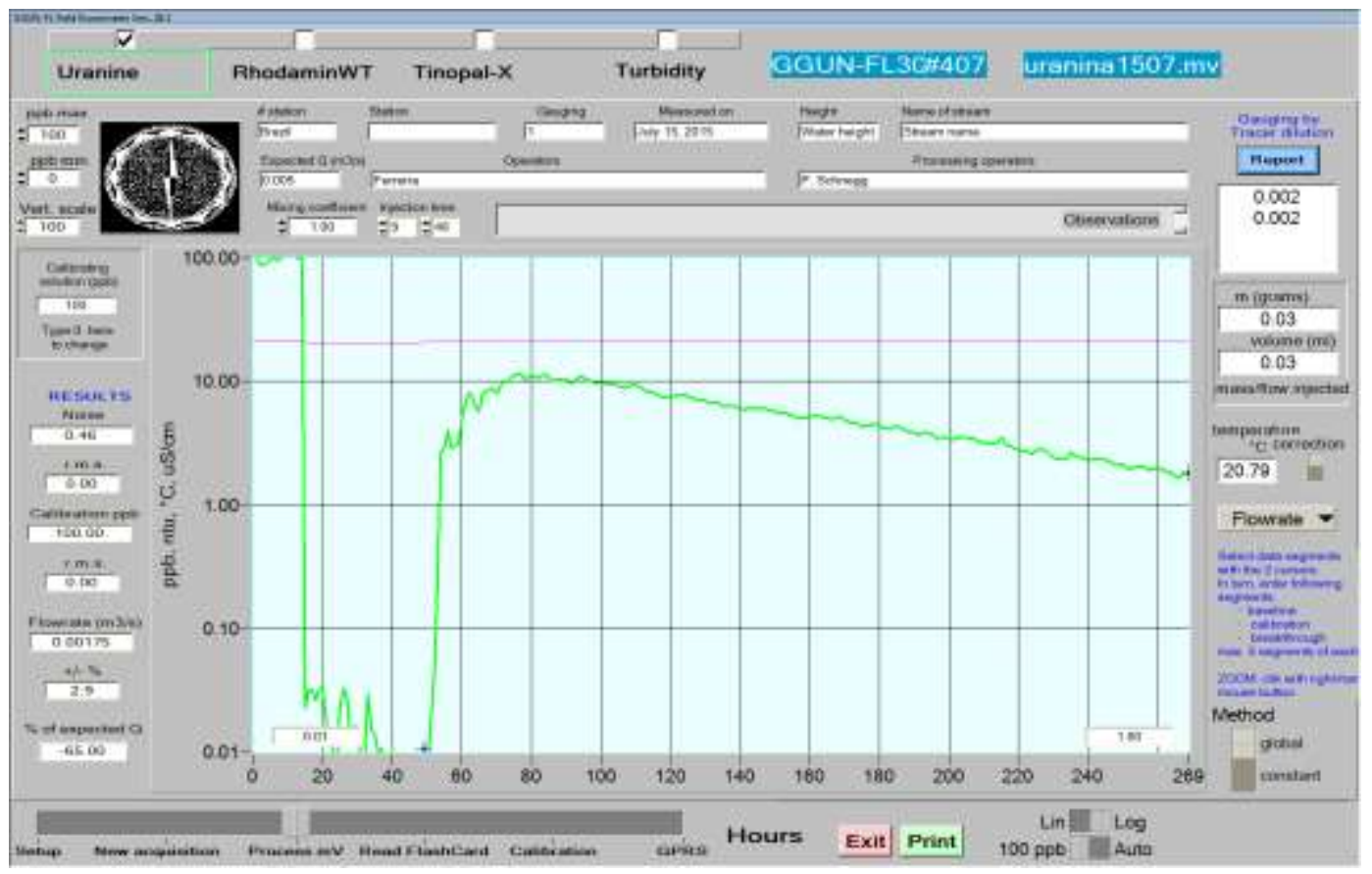


FERREIRA, V.V.M; CHAGAS, C.J.; ROCHA, Z.; MOREIRA, R.M.; SANTOS, T.O.; FONSECA, R.L.M.; LEMOS, N.C.; FONSECA, E.S.; FERRAZ, T.; MENEZES, M.A.B.C.

Figura 5 - Vazão a montante da seção 1 - 1,75 litros/segundo (15/07/2015). Traçador: fluoresceína Figure 5 - Flow upstream section 1 - 1.75 liters/second (07/15/2015). Tracer: fluorescein.

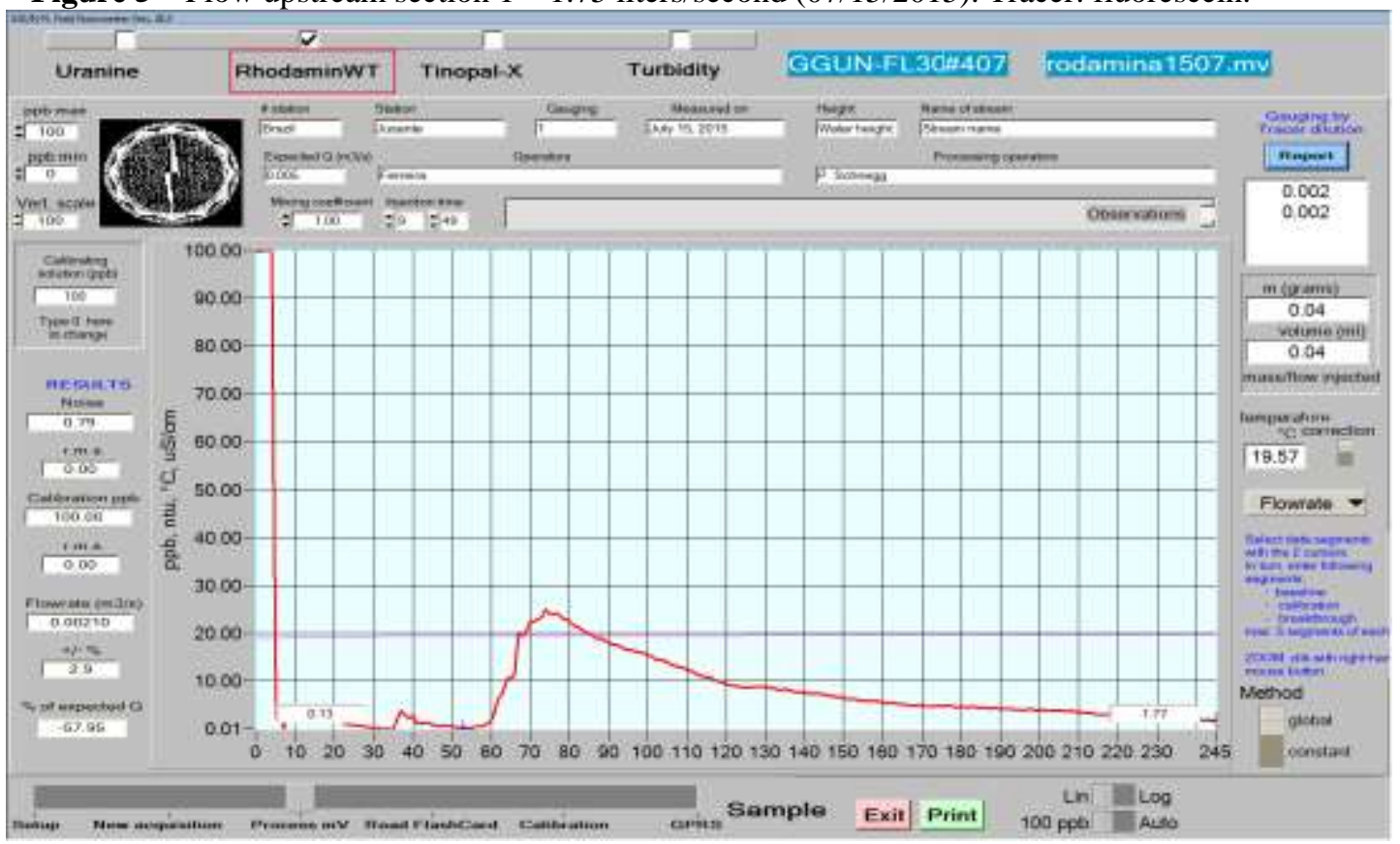

Figura 6 - Vazão a jusante da seção 1 - 2,10 litros/segundo (15/07/2015). Traçador: rodamina Figure 6 - Flow downstream section 1 - 2.10 liters/second (07/15/2015). Tracer: rhodamine.

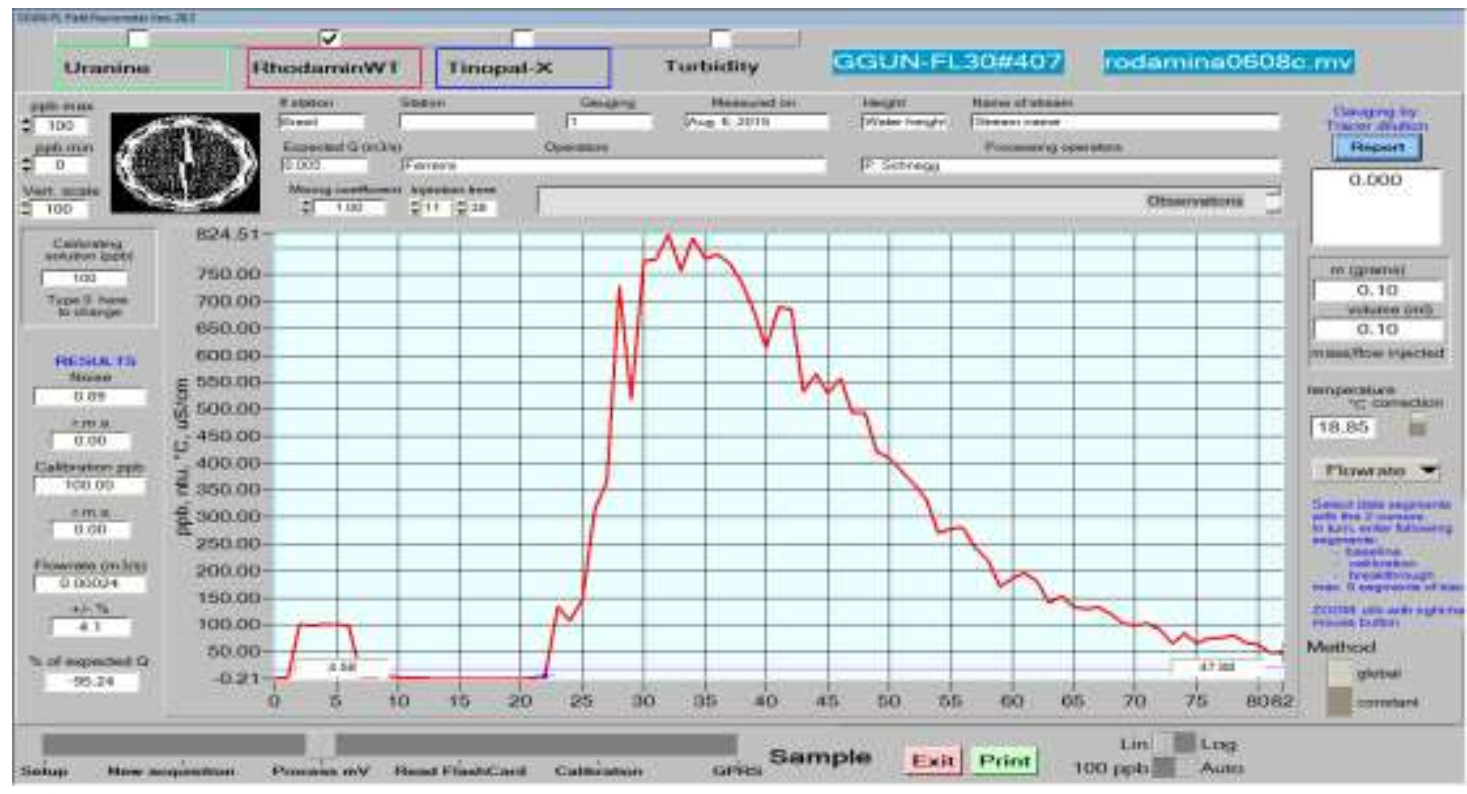

Figura 7 - Vazão a montante da seção 2 - 2,4 litros/segundo (03/08/2015). Traçador: rodamina Figure 7 - Flow upstream section $2-2.4$ liters/second (08/03/2015). Tracer: rhodamine. 




Figura 8 - Vazão a jusante da seção 2 - 2,8 litros/segundo (03/08/2015). Traçador: rodamina

Figure 8 - Flow downstream section 2 - 2.8 liters/second (08/03/2015). Tracer: rhodamine.

A Tabela 5 contém os resultados da campanha de setembro de 2015, quando as coletas de água foram realizadas a jusante das duas seções estudadas nas campanhas anteriores, em locais onde também foram encontrados picos de radônio (conforme Figura 2). Ob- serva-se que nessa campanha os valores das concentrações de radônio 222 variaram entre 1 e $39 \mathrm{KBq} / \mathrm{m}^{3}$, o que indica também a existência de pontos ou seções de descarga no trecho.

Tabela 5 - Concentrações de ${ }^{222} \mathrm{Rn}$ nos pontos da $3^{\mathrm{a}}$ campanha

Table 5 -Concentrations of ${ }^{222} \mathrm{Rn}$ at the third campaign points

\begin{tabular}{|c|c|c|c|c|c|}
\hline Ponto & $\begin{array}{l}\text { Concentração de } \\
\text { radônio medida } \\
\quad\left(\mathbf{k B q} / \mathbf{m}^{3}\right)\end{array}$ & $\begin{array}{c}\text { Data e } \\
\text { hora da } \\
\text { coleta }\end{array}$ & $\begin{array}{c}\text { Data e } \\
\text { hora da } \\
\text { leitura }\end{array}$ & $\begin{array}{l}\text { Tempo de- } \\
\text { corrido entre } \\
\text { a coleta e } \\
\text { leitura (dias) }\end{array}$ & $\begin{array}{c}\text { Concentração de } \\
\text { radônio corrigi- } \\
\text { da e }\left(\mathbf{k B q} / \mathbf{m}^{\mathbf{3}}\right)\end{array}$ \\
\hline 1 & $2,93 \pm 0,83$ & $\begin{array}{c}28 / 09 / 15 \\
16: 20\end{array}$ & $\begin{array}{c}28 / 09 / 15 \\
16: 20\end{array}$ & 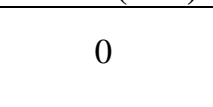 & $2,93 \pm 0,83$ \\
\hline $2 \mathrm{~A}$ & $5,26 \pm 1,03$ & $\begin{array}{c}28 / 09 / 15 \\
16: 30 \\
28 / 09 / 15\end{array}$ & $\begin{array}{c}28 / 09 / 15 \\
17: 06 \\
28 / 09 / 15\end{array}$ & 0,025 & $5,28 \pm 1,03$ \\
\hline $2 \mathrm{~B}$ & $6,19 \pm 0,52$ & $\begin{array}{c}16: 33 \\
28 / 09 / 15\end{array}$ & $\begin{array}{l}17: 45 \\
28 / 09 / 15\end{array}$ & 0,05 & $6,25 \pm 0,52$ \\
\hline $3 \mathrm{~A}$ & $4,68 \pm 0,64$ & $\begin{array}{c}16: 50 \\
28 / 09 / 15\end{array}$ & $\begin{array}{c}19: 23 \\
28 / 09 / 15\end{array}$ & 0,11 & $4,77 \pm 0,65$ \\
\hline $3 \mathrm{~B}$ & $4,46 \pm 1,2$ & $\begin{array}{c}16: 53 \\
28 / 09 / 15\end{array}$ & $\begin{array}{c}20: 06 \\
28 / 09 / 15\end{array}$ & 0,134 & $4,57 \pm 1,23$ \\
\hline $4 \mathrm{~A}$ & $1,29 \pm 0,17$ & $\begin{array}{c}17: 05 \\
28 / 09 / 15\end{array}$ & $\begin{array}{c}21: 15 \\
28 / 09 / 15\end{array}$ & 0,173 & $1,33 \pm 0,17$ \\
\hline $4 B$ & $1,57 \pm 0,42$ & $\begin{array}{c}17: 07 \\
28 / 09 / 15\end{array}$ & $\begin{array}{c}22: 04 \\
29 / 09 / 15\end{array}$ & 0,206 & $1,63 \pm 0,44$ \\
\hline $5 \mathrm{~A}$ & $6,76 \pm 1,53$ & $\begin{array}{c}17: 10 \\
28 / 09 / 15\end{array}$ & $\begin{array}{c}09: 05 \\
29 / 09 / 15\end{array}$ & 0,063 & $7,62 \pm 1,72$ \\
\hline $5 B$ & $10,7 \pm 1,03$ & $\begin{array}{c}17: 17 \\
28 / 09 / 15\end{array}$ & $\begin{array}{c}09: 53 \\
29 / 09 / 15\end{array}$ & 0708 & $12,12 \pm 1,17$ \\
\hline $6 \mathrm{~A}$ & $4,04 \pm 0,22$ & $17: 30$ & $10: 30$ & $0, / 08$ & $4,59 \pm 0,24$ \\
\hline
\end{tabular}


FERREIRA, V.V.M; CHAGAS, C.J.; ROCHA, Z.; MOREIRA, R.M.; SANTOS, T.O.; FONSECA, R.L.M.; LEMOS, N.C.; FONSECA, E.S.; FERRAZ, T.; MENEZES, M.A.B.C.

Tabela 5 - Concentrações de ${ }^{222} \mathrm{Rn}$ nos pontos da $3^{\mathrm{a}}$ campanha

Table 5 - Concentrations of ${ }^{222} \mathrm{Rn}$ at the third campaign points

\begin{tabular}{|c|c|c|c|c|c|}
\hline Ponto & $\begin{array}{l}\text { Concentração de } \\
\text { radônio medida } \\
\quad\left(\mathbf{k B q} / \mathbf{m}^{3}\right)\end{array}$ & $\begin{array}{c}\text { Data e } \\
\text { hora da } \\
\text { coleta }\end{array}$ & $\begin{array}{c}\text { Data e } \\
\text { hora da } \\
\text { leitura }\end{array}$ & $\begin{array}{l}\text { Tempo de- } \\
\text { corrido entre } \\
\text { a coleta e } \\
\text { leitura (dias) }\end{array}$ & $\begin{array}{l}\text { Concentração de } \\
\text { radônio corrigi- } \\
\text { da e }\left(\mathbf{k B q} / \mathbf{m}^{\mathbf{3}}\right)\end{array}$ \\
\hline \multirow{3}{*}{$6 \mathrm{~B}$} & \multirow{3}{*}{$4,44 \pm 0,71$} & $28 / 09 / 15$ & $29 / 09 / 15$ & \multirow{2}{*}{0,741} & \multirow{3}{*}{$5,07 \pm 0,81$} \\
\hline & & $17: 33$ & 11:20 & & \\
\hline & & 28/09/15 & $29 / 09 / 15$ & \multirow[t]{2}{*}{0,764} & \\
\hline $7 \mathrm{~A}$ & $3,86 \pm 0,8$ & $17: 35$ & $11: 55$ & & $4,43 \pm 0,92$ \\
\hline & & $28 / 09 / 15$ & $29 / 09 / 15$ & \multirow{2}{*}{0,800} & \\
\hline $7 \mathrm{~B}$ & $3,71 \pm 1,15$ & $17: 37$ & $12: 50$ & & $4,26 \pm 1,33$ \\
\hline & & 28/09/15 & 29/09/15 & \multirow{2}{*}{0,826} & \\
\hline 8 & $8,52 \pm 1,68$ & 17:50 & $13: 40$ & & $9,89 \pm 1,94$ \\
\hline & & 28/09/15 & $\begin{array}{c}29 / 09 / 15 \\
14 \cdot 53\end{array}$ & \multirow[t]{2}{*}{0,870} & \\
\hline $9 \mathrm{~A}$ & $9,23 \pm 1,1$ & 18:00 & $14: 53$ & & $10,79 \pm 1,29$ \\
\hline $9 \mathrm{~B}$ & $15,5 \pm 1,1$ & $\begin{array}{c}28 / 09 / 15 \\
18: 03\end{array}$ & $\begin{array}{c}30 / 09 / 15 \\
11: 28\end{array}$ & 1,73 & $21,15 \pm 1,5$ \\
\hline & & $28 / 09 / 2015$ & $30 / 09 / 2015$ & \multirow{2}{*}{1,82} & \\
\hline $10 \mathrm{~A}$ & $23,3 \pm 2,13$ & $18: 10$ & $13: 55$ & & $32,35 \pm 2,96$ \\
\hline & & 28/09/15 & $30 / 09 / 15$ & \multirow{2}{*}{1,86} & \\
\hline $10 \mathrm{~B}$ & $21,6 \pm 3,82$ & 18:13 & $14: 56$ & & $30,2 \pm 5,3$ \\
\hline $11 \mathrm{~A}$ & $6,36 \pm 1,16$ & $\begin{array}{c}29 / 09 / 2015 \\
13: 00\end{array}$ & $\begin{array}{c}30 / 09 / 2015 \\
15: 35\end{array}$ & 1,11 & $7,76 \pm 1,42$ \\
\hline & & $29 / 09 / 2015$ & $30 / 09 / 2015$ & \multirow{2}{*}{1,13} & \\
\hline $11 \mathrm{~B}$ & $5,71 \pm 0,55$ & 13:02 & $16: 10$ & & $6,99 \pm 0,68$ \\
\hline $12 \mathrm{~A}$ & $0,75 \pm 0,295$ & $\begin{array}{c}29 / 09 / 15 \\
13: 10\end{array}$ & 1/10/15 10:05 & 1,87 & $1,05 \pm 0,41$ \\
\hline $12 \mathrm{~B}$ & $6,61 \pm 0,65$ & $\begin{array}{c}29 / 09 / 15 \\
13: 12\end{array}$ & 1/10/15 11:09 & 1,91 & $9,33 \pm 0,92$ \\
\hline & $0,01 \perp 0,0 J$ & $29 / 09 / 15$ & $1 / 10 / 15$ 12:20 & \multirow{2}{*}{1,96} & \\
\hline $13 \mathrm{~A}$ & $5,21 \pm 1,09$ & 13:20 & $1 / 10 / 1512.20$ & & $7,41 \pm 1,55$ \\
\hline $13 \mathrm{~B}$ & $10,4 \pm 1,74$ & $\begin{array}{c}29 / 09 / 15 \\
13: 22\end{array}$ & $1 / 10 / 15$ 13:20 & 1,99 & $14,9 \pm 2,49$ \\
\hline & & $29 / 09 / 15$ & \multirow{2}{*}{ 1/10/15 14:00 } & \multirow[t]{2}{*}{2,02} & \\
\hline $14 \mathrm{~A}$ & $8,72 \pm 0,659$ & $13: 33$ & & & $12,54 \pm 0,95$ \\
\hline 14B & $11,3 \pm 1,07$ & $\begin{array}{c}29 / 09 / 15 \\
13: 44\end{array}$ & 1/10/15 14:37 & 2,04 & $16,3 \pm 1,54$ \\
\hline $15 \mathrm{~A}$ & $16.1+1.64$ & $\begin{array}{c}29 / 09 / 15 \\
14: 50\end{array}$ & $1 / 10 / 1515: 15$ & 2,02 & $23,15+2,36$ \\
\hline & 10, I, & $29 / 09 / 15$ & \multirow{2}{*}{$1 / 10 / 15$ 15:50 } & \multirow{2}{*}{2,04} & \\
\hline $15 B$ & $19,8 \pm 0,66$ & $14: 52$ & & & $28,59+0,95$ \\
\hline $16 \mathrm{~A}$ & $25,9 \pm 2,44$ & $\begin{array}{c}29 / 09 / 15 \\
14: 03\end{array}$ & $1 / 10 / 1516: 25$ & 2,10 & $37,79+3,56$ \\
\hline $16 \mathrm{~B}$ & $27 \pm 2,89$ & $\begin{array}{c}29 / 09 / 15 \\
14: 05\end{array}$ & 1/10/15 17:00 & 2,12 & $39,55+4,23$ \\
\hline & & $\begin{array}{c}29 / 09 / 15 \\
14 \cdot 12\end{array}$ & 2/10/15 14:26 & 3,01 & \\
\hline $17 \mathrm{~A}$ & $18,5 \pm 1,61$ & $\begin{array}{c}14: 12 \\
29 / 09 / 15\end{array}$ & & & $31,8+2,77$ \\
\hline 17B & $13,1 \pm 1,12$ & $\begin{array}{l}29 / 09 / 15 \\
14: 14\end{array}$ & $\begin{array}{l}2 / 10 / 15 \\
9: 50\end{array}$ & 2,82 & $21,75+1,86$ \\
\hline $18 \mathrm{~A}$ & $17 \pm 1,59$ & $\begin{array}{c}29 / 09 / 15 \\
14: 40\end{array}$ & 2/10/15 11:40 & 2,86 & $28,52+2,67$ \\
\hline $18 \mathrm{~B}$ & $17,3 \pm 1,65$ & $\begin{array}{c}29 / 09 / 15 \\
14: 42\end{array}$ & 2/10/15 12:25 & 2,90 & $29,18+2,78$ \\
\hline & & 29/09/15 & $2 / 10 / 15$ 13:03 & 2,92 & \\
\hline $19 \mathrm{~A}$ & $19 \pm 3,39$ & 14:53 & $2 / 10 / 15$ 15:03 & 2,92 & $32,16+5,74$ \\
\hline $19 B$ & $22,3 \pm 1,23$ & $\begin{array}{c}29 / 09 / 15 \\
14: 55\end{array}$ & 2/10/15 13:38 & 2,95 & $37,9+2,09$ \\
\hline
\end{tabular}


Tabela 5 - Concentrações de ${ }^{222} \mathrm{Rn}$ nos pontos da $3^{\mathrm{a}}$ campanha Table 5 - Concentrations of ${ }^{222} \mathrm{Rn}$ at the third campaign points

\begin{tabular}{|c|c|c|c|c|c|}
\hline Ponto & $\begin{array}{l}\text { Concentração de } \\
\text { radônio medida } \\
\qquad\left(\mathbf{k B q} / \mathbf{m}^{3}\right)\end{array}$ & $\begin{array}{c}\text { Data e } \\
\text { hora da } \\
\text { coleta } \\
\end{array}$ & $\begin{array}{c}\text { Data e } \\
\text { hora da } \\
\text { leitura }\end{array}$ & $\begin{array}{c}\text { Tempo de- } \\
\text { corrido entre } \\
\text { a coleta e } \\
\text { leitura (dias) }\end{array}$ & $\begin{array}{l}\text { Concentração de } \\
\text { radônio corrigi- } \\
\text { da e }\left(\mathbf{k B q} / \mathbf{m}^{\mathbf{3}}\right)\end{array}$ \\
\hline $20 \mathrm{~A}$ & $16 \pm 1,05$ & $\begin{array}{c}29 / 09 / 15 \\
15: 05\end{array}$ & 2/10/15 11:05 & 2,83 & $26,64+1,75$ \\
\hline $20 B$ & $15,5 \pm 1,92$ & $\begin{array}{c}29 / 09 / 15 \\
15: 07\end{array}$ & 2/10/15 10:26 & 2,80 & $25,68+3,18$ \\
\hline $21 \mathrm{~A}$ & $0,82 \pm 0,47$ & $\begin{array}{c}29 / 09 / 15 \\
9: 35\end{array}$ & $5 / 10 / 1510: 15$ & 6,03 & $2,43+1,39$ \\
\hline $21 \mathrm{~B}$ & $0,68 \pm 0,25$ & $\begin{array}{c}29 / 09 / 15 \\
9: 37\end{array}$ & $5 / 10 / 1512: 30$ & 6,12 & $2,04+0,74$ \\
\hline $22 \mathrm{~A}$ & $0,99 \pm 0,40$ & $\begin{array}{c}29 / 09 / 15 \\
9: 45\end{array}$ & 5/10/15 13:10 & 6,14 & $3,02+1,22$ \\
\hline $22 \mathrm{~B}$ & $0,75 \pm 0,27$ & $\begin{array}{c}29 / 09 / 15 \\
9: 47\end{array}$ & $5 / 10 / 15$ 14:00 & 6,18 & $2,28+0,81$ \\
\hline $23 \mathrm{~A}$ & $1,14 \pm 0,42$ & $\begin{array}{c}29 / 09 / 15 \\
9: 55\end{array}$ & $5 / 10 / 1514: 40$ & 6,20 & $3,48+1,28$ \\
\hline $23 \mathrm{~B}$ & $0,96 \pm 0,54$ & $\begin{array}{c}29 / 09 / 15 \\
9: 57\end{array}$ & $5 / 10 / 15$ 15:36 & 6,24 & $2,96+1,65$ \\
\hline 24 & $0,25 \pm 0,14$ & $\begin{array}{c}29 / 09 / 15 \\
10: 07\end{array}$ & $\begin{array}{c}6 / 10 / 15 \\
9: 30\end{array}$ & 6,97 & $0,87+0,48$ \\
\hline
\end{tabular}

No que se refere às medidas de vazão, de acordo com as instruções do fabricante e com os resultados anteriores, a partir desta campanha não foi mais usada a rodamina, apenas a uranina. Os resultados das vazões desta campanha foram descartados. Segundo contato com o fabricante, o problema deveuse ao fato da elevada turbidez da água utilizada para a calibração do equipamento, coletada em um trecho do córrego onde a velocidade era lenta. Os experimentos foram posteriormente repetidos e apresentaram bons resultados, tendo sido efetuadas 4 medidas de vazão, cujos resultados foram crescentes. As duas primeiras medidas foram feitas nos limites da seção 1 , a $3^{a}$ medida na seção 2 e a última medida após todo o trecho de coleta apresentado na Tabela 5. As Figuras 9 a 12 apresentam os resultados em questão. Os incrementos obtidos quando das medições de vazões juntamente com a presença de radônio 222 em concentrações elevadas em alguns setores do Córrego do Fundão, correspondem e caracterizam as descargas de águas subterrâneas nos trechos em estudo, considerando-se a ausência de chuvas nos períodos de análises/medições. Estas descargas explicam à manutenção do nível de água a jusante da área de estudo, de acordo com os dados de uma estação fluviométrica monitorada no escopo de outro projeto de pesquisa. 
FERREIRA, V.V.M; CHAGAS, C.J.; ROCHA, Z.; MOREIRA, R.M.; SANTOS, T.O.; FONSECA, R.L.M.; LEMOS, N.C.; FONSECA, E.S.; FERRAZ, T.; MENEZES, M.A.B.C.



Figura 9 - Vazão a montante da seção 1 - 1,13 litros/segundo (16/12/2015). Traçador: fluoresceína Figure 9 - Flow upstream section 1 - 1.13 liters/second (12/16/2015). Tracer: fluorescein

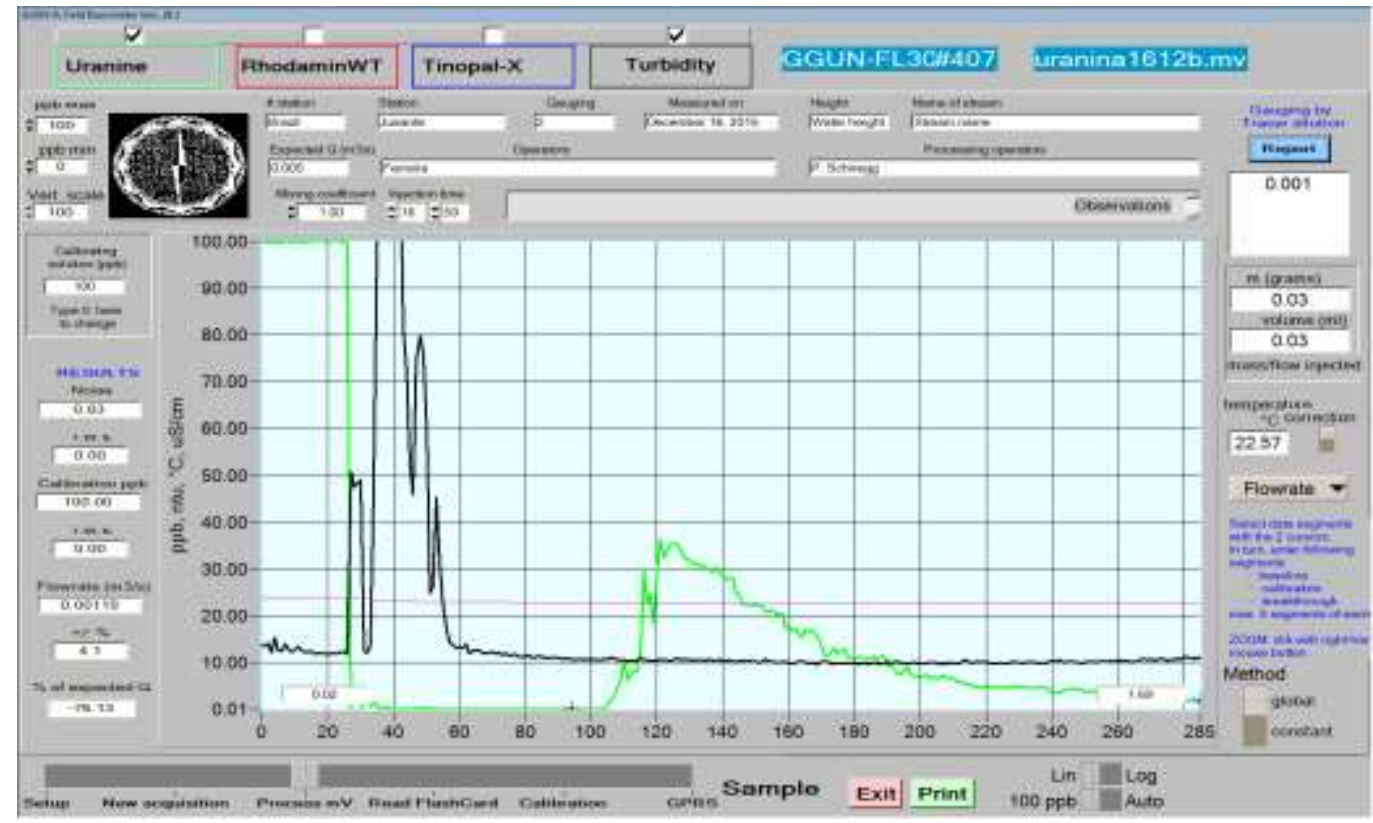

Figura 10 - Vazão a jusante da seção 1 - 1,19 litros/segundo (16/12/2015). Traçador: fluoresceína

Figure 10 - Flow downstream section 1 - 1.19 liters/second (12/16/2015). Tracer: fluorescein 


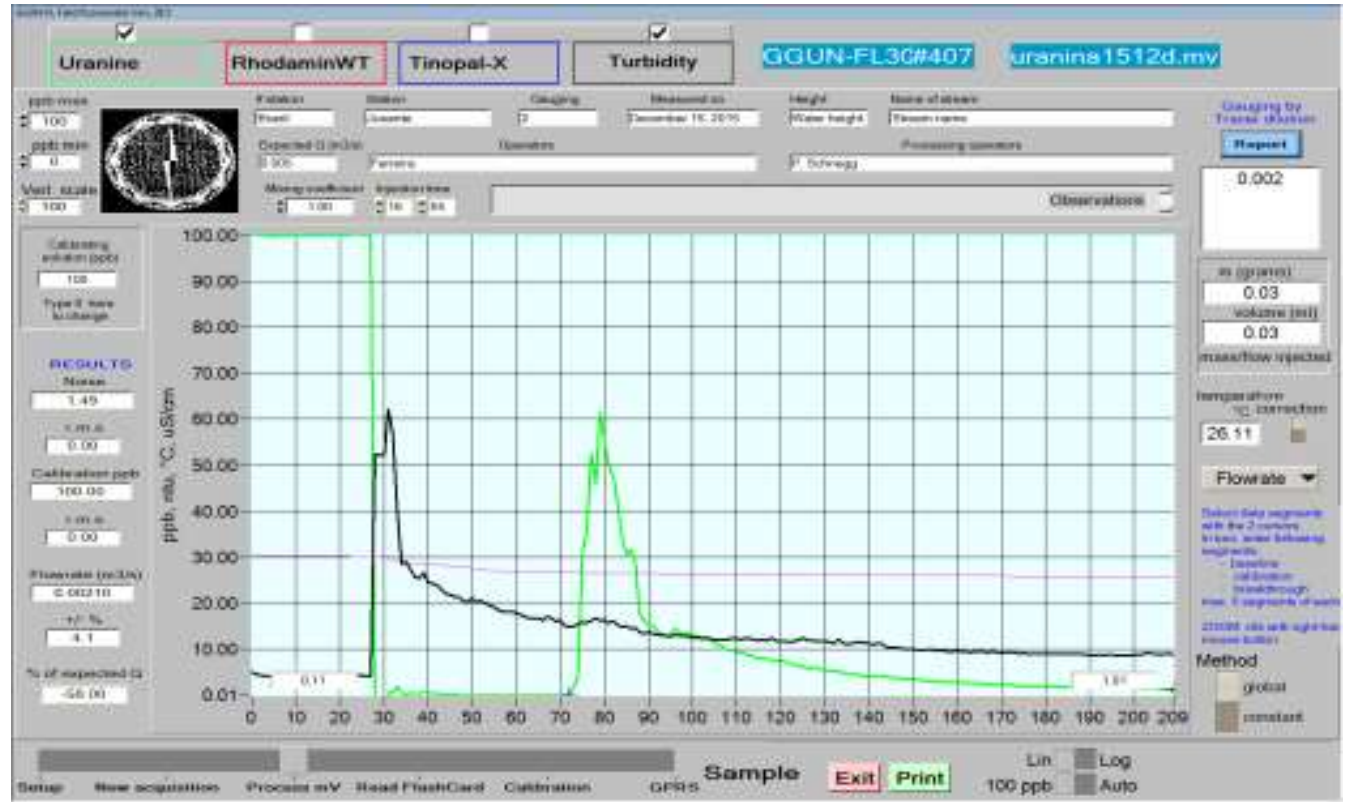

Figura 11 - Vazão a jusante da seção 2 - 2,1 litros/segundo (15/12/2015). Traçador: fluoresceína

Figure 11 - Flow downstream section 2 - 2.1 liters/second (12/15/2015). Tracer: fluorescein

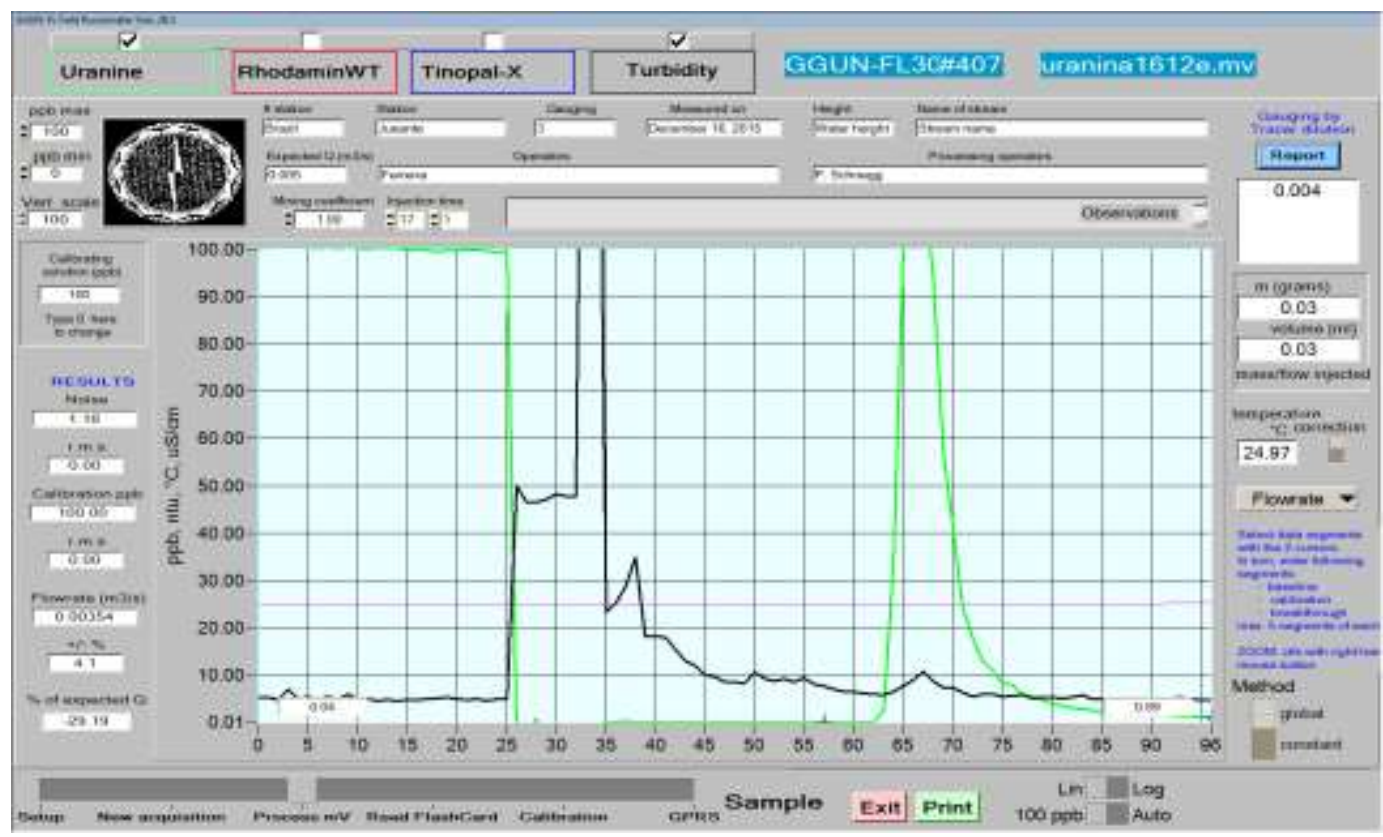

Figura 12 - Vazão no exutório do Córrego - 3,54 litros/segundo (16/12/2015). Traçador: fluoresceína

Figure 12 - Flow at the end of the stream - 3.54 liters/second (12/16/2015). Tracer: fluorescein

Com o auxílio do software MINITAB foi feita uma avaliação estatística dos resultados das Tabelas 1 a 5, sendo os resultados apresentados nas Figuras 13 a 17 e na Tabela
6. É possível visualizar em todas as figuras a presença de picos de concentração cujos valores são bem acima da média. 
FERREIRA, V.V.M; CHAGAS, C.J.; ROCHA, Z.; MOREIRA, R.M.; SANTOS, T.O.; FONSECA, R.L.M.; LEMOS, N.C.; FONSECA, E.S.; FERRAZ, T.; MENEZES, M.A.B.C.

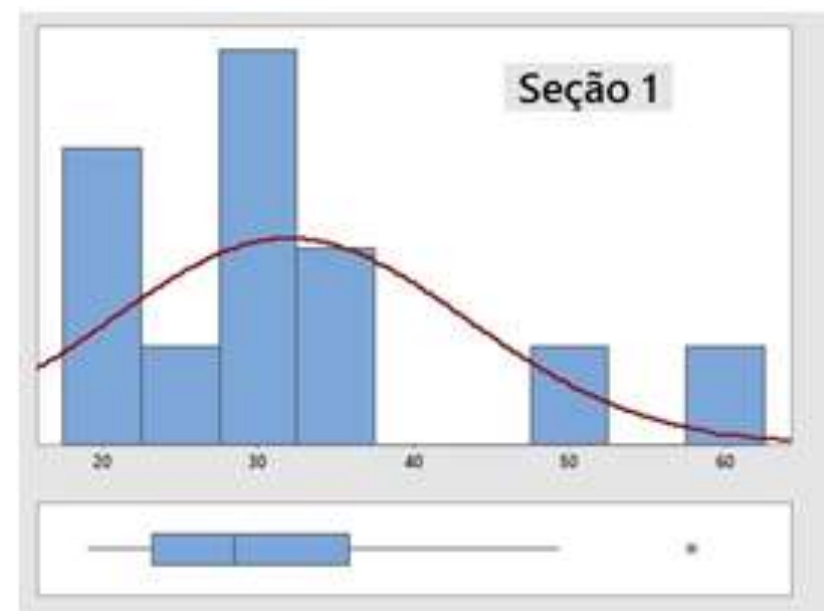

Figura 13 - Distribuição normal dos resultados da Tabela 1 Figure 13 - Normal distribution of the Table 1 results

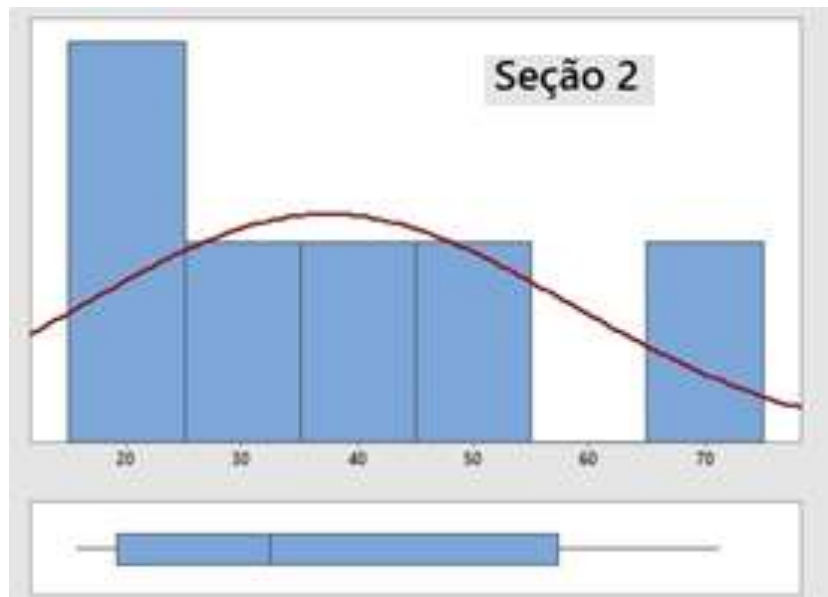

Figura 14 - Distribuição normal dos resultados da Tabela 2 Figure 14 - Normal distribution of the Table 2 results

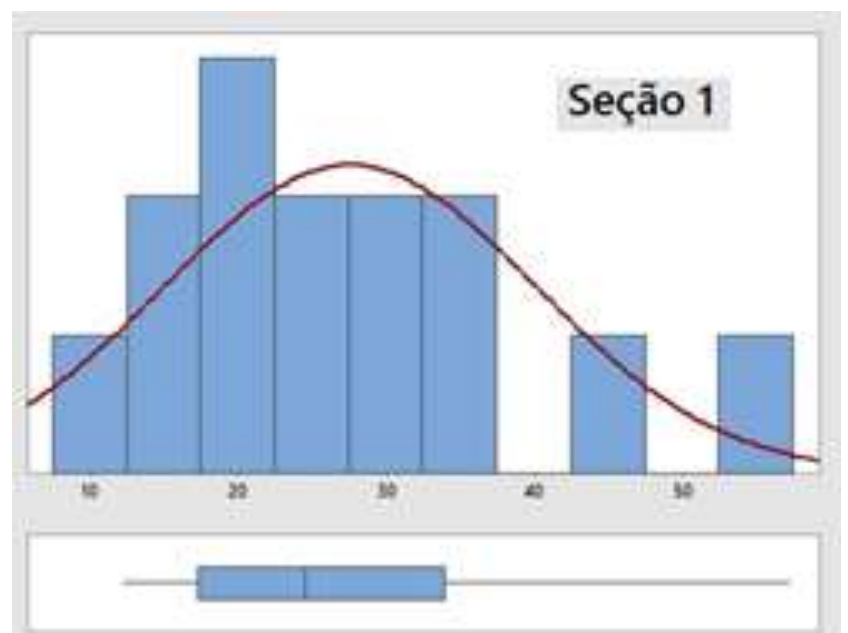

Figura 15 - Distribuição normal dos resultados da Tabela 3 Figure 15 - Normal distribution of the Table 3 results 


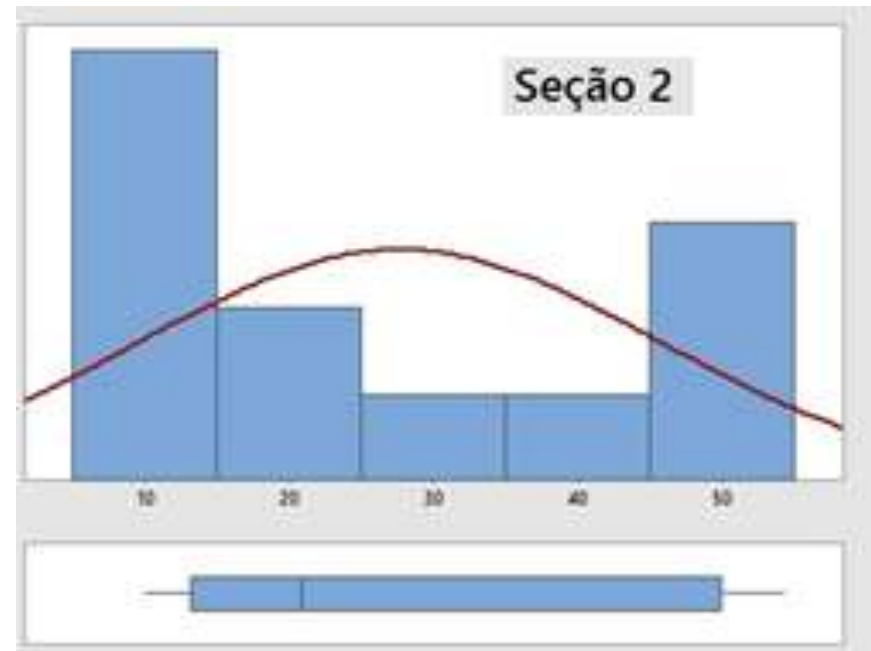

Figura 16 - Distribuição normal dos resultados da Tabela 4 Figure 16 - Normal distribution of the Table 4 results

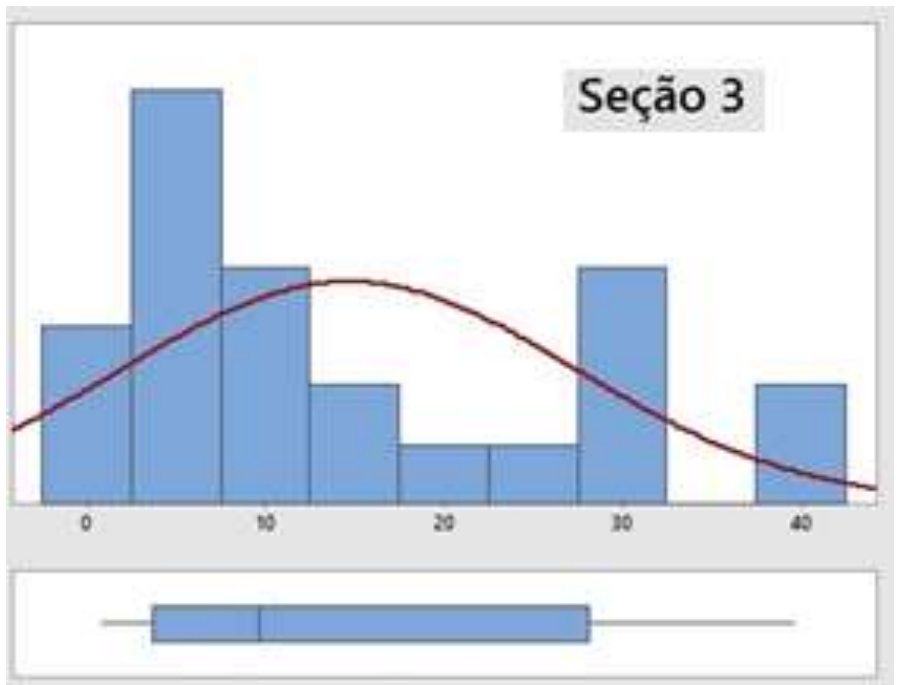

Figura 17 - Distribuição normal dos resultados da Tabela 5

Figure 17 - Normal distribution of the Table 5 results

Tabela 6 - Tratamento estatístico das leituras de radônio 222

Table 6 - Statistical treatment of the ${ }^{222} \mathrm{Rn}$ readings

\begin{tabular}{lccccc}
\hline Parâmetros estatísticos & $\begin{array}{c}\text { Seção 1 } \\
\text { Fevereiro }\end{array}$ & $\begin{array}{c}\text { Seção 2 } \\
\text { Fevereiro }\end{array}$ & $\begin{array}{c}\text { Seção 1 } \\
\text { Julho }\end{array}$ & $\begin{array}{c}\text { Seção 2 } \\
\text { Julho }\end{array}$ & $\begin{array}{c}\text { Seção 3 } \\
\text { Setembro }\end{array}$ \\
\hline Média & $\mathbf{2 0 1 5}$ & $\mathbf{2 0 1 5}$ & $\mathbf{2 0 1 5}$ & $\mathbf{2 0 1 5}$ & $\mathbf{2 0 1 5}$ \\
Desvio padrão & 32,006 & 37,382 & 27,599 & 27,712 & 14,681 \\
Variância & 11,468 & 21,025 & 12,547 & 17,902 & 12,748 \\
Assimetria & 131,513 & 442,069 & 157,427 & 320,498 & 162,502 \\
Curtose & 1,293 & 0,840 & 1,193 & 0,665 & 0,703 \\
Número de amostras & 1,339 & $-0,304$ & 1,151 & $-1,429$ & $-0,998$ \\
Valor mínimo & 12 & $6^{*}$ & 14 & 12 & $24 *$ \\
1o quartil & 19,140 & 15,750 & 12,260 & 10,080 & 0,870 \\
Mediana & 23,205 & 19,072 & 17,378 & 13,250 & 3,717 \\
3o quartil & 28,495 & 32,320 & 24,540 & 20,860 & 9,610 \\
& 35,802 & 57,235 & 33,922 & 49,973 & 28,102 \\
\hline
\end{tabular}


Tabela 6 - Tratamento estatístico das leituras de radônio 222

Table 6 - Statistical treatment of the ${ }^{222} \mathrm{Rn}$ readings

\begin{tabular}{|c|c|c|c|c|c|}
\hline Parâmetros estatísticos & $\begin{array}{c}\text { Seção 1 } \\
\text { Fevereiro } \\
2015 \\
\end{array}$ & $\begin{array}{c}\text { Seção } 2 \\
\text { Fevereiro } \\
2015\end{array}$ & $\begin{array}{c}\text { Seção } 1 \\
\text { Julho } \\
2015\end{array}$ & $\begin{array}{c}\text { Seção } 2 \\
\text { Julho } \\
2015\end{array}$ & $\begin{array}{c}\text { Seção } 3 \\
\text { Setembro } \\
2015 \\
\end{array}$ \\
\hline Valor máximo & 57,880 & 71,110 & 57,280 & 54,380 & 39,550 \\
\hline $\begin{array}{l}\text { 95\% de intervalo de confi- } \\
\text { ança para a média }\end{array}$ & $\begin{array}{l}24,719- \\
39,292\end{array}$ & $\begin{array}{l}15,317- \\
59,447\end{array}$ & $\begin{array}{c}20,354- \\
34,843\end{array}$ & $\begin{array}{c}16,337- \\
39,086\end{array}$ & $\begin{array}{l}9,298- \\
20,064\end{array}$ \\
\hline $\begin{array}{l}95 \% \text { de intervalo de confi- } \\
\text { ança para a mediana }\end{array}$ & $\begin{array}{c}23,269- \\
35,799\end{array}$ & $\begin{array}{c}17,332- \\
64,503\end{array}$ & $\begin{array}{l}17,483- \\
33,039\end{array}$ & $\begin{array}{c}13,268- \\
49,836\end{array}$ & $\begin{array}{l}4,711- \\
22,101\end{array}$ \\
\hline $\begin{array}{l}95 \% \text { de intervalo de confi- } \\
\text { ança para o DP }\end{array}$ & $\begin{array}{l}8,124- \\
19,471\end{array}$ & $\begin{array}{l}13,124- \\
51,567\end{array}$ & $\begin{array}{l}9,096- \\
20,214\end{array}$ & $\begin{array}{l}12,682- \\
30,396 \\
\end{array}$ & $\begin{array}{l}9,908- \\
17,882\end{array}$ \\
\hline
\end{tabular}

* - no caso de duas medidas no mesmo ponto o menor valor foi descartado.

\section{CONCLUSÕES}

A presença de radônio 222 nas águas da bacia de Juatuba mostrou-se um eficiente parâmetro para identificação de seções de descarga ao longo do Córrego do Fundão. Mesmo com a prolongada ausência de chuvas na área, não houve uma redução significativa do nível de água nos trechos em estudo, o que pode ser explicado pelas descargas existentes no local.

Os resultados obtidos foram capazes de identificar algumas seções de descarga no córrego em estudo, caracterizadas pelo aumento das vazões (mensuradas com o auxílio

\section{REFERÊNCIAS}

BANDEIRA, J. V. Desenvolvimento de técnicas nucleares e correlatas para estudos em Hidrologia Urbana: aplicações na Bacia Hidrográfica da Pampulha e no Rio das Velhas, MG. Belo Horizonte, MG, Brasil, 2004. 276 p. Tese (Doutorado em Saneamento, Meio Ambiente e Recursos Hídricos). Universidade Federal de Minas Gerais.

BANDEIRA, J. V.; FERREIRA, V. V. M.; SALIM, L. H.; VIEIRA, N. S.; MENEGHINI, M. S. M.; SALES, D. M.; JUNQUEIRA, M. V.; CARVALHO, M. D.; MOTA, H. R. Hydrosedimentological studies in the Paciência dam, southeastern Brazil. Latin American Journal of Sedimentology and Basin Analysis, v. 19, n. 2, p. 89-103, 2012.

BEKELE, E.; PATTERSON, B.; TOZE, S.; FURNESS, A.; HIGGINSON, S.; SHACKLETON, M. Aquifer residence times for recycled water estimated using chemical tracers and the propagation of temperature signals at a managed aquifer recharge site in Águas Subterrâneas (2016) 30(1): 79-98. de um fluorímetro) e pela presença de radônio $222 \mathrm{em}$ concentrações elevadas nas amostras de águas superficiais coletadas e analisadas.

Os equipamentos RAD 7 e GGUN FL-30, e o uso de traçadores fluorescentes mostraram-se adequados ao desenvolvimento das atividades no escopo deste projeto.

\section{AGRADECIMENTOS}

A FAPEMIG e a FUNDEP. Aos colegas Aline Fabiane, Pedro Dutra e Joir Genaro.

Australia. Hydrogeology Journal, v. 22, n. 6, p. 1383-1401, 2014.

BURNETT, W. C.; PETERSON, R.; MOORE, W. S.; OLIVEIRA, J. Radon and radium isotopes as tracer of submarine groundwater discharge - Results from the Ubatuba, Brazil SGD assessment intercomparison. Estuarine, Coastal and Shelf Science, v. 76, n. 3, p. 501-511, 2008.

CETEC - Fundação Centro Tecnológico de Minas Gerais. Relatório final. Belo Horizonte: 1983. Determinação do funcionamento hidráulico de aquíferos a partir de parâmetros hídricos. Secretaria de Ciência e Tecnologia do Estado de Minas Gerais.

CHANYOTHA, S.; CHUTIMA, K.; BURNETT, W. C.; LANE-SMITH, D.; SIMKO, J. Prospecting for groundwater discharge in the canals of Bangkok via natural radon and thoron. Journal of Hydrology, v. 519, Part B, p. 1485-1492, 2014. 
CLASON, C. C.; COCH, C.; JARSJO, J.; BRUGGER, K.; JANSSON, P.; ROSQVIST, G. Dye tracing to determine flow properties of hydrocarbon-polluted Rabots glaciär, Kebnekaise, Sweden. Hydrology and Earth System Sciences, v. 19, p. 2701-2715, 2015.

CLOSE, M.; MATTHEWS, M.; BURBERY, L.; ABRAHAM, P.; SCOTT, D. Use of radon to characterize surface water recharge to groundwater. Journal of Hydrology (New Zealand), v. 53, n. 2, p. 113-127, 2014.

CORREA, J. N. Avaliação dos níveis de concentração de radônio em ambientes e águas de poços no Estado do Paraná. Curitiba, PR, Brasil, 2011. 112 p. Tese (Doutorado em Engenharia Elétrica e Informática Industrial). Universidade Federal Tecnológica do Paraná.

DAVIS, S. N.; THOMPSON, G. M.; BENTLEY, H. W.; STILES, G. Ground-water tracers - a short review. Ground Water, v. 18, n. 1, p. 14-23, 1980.

DIMOVA, N. T.; BURNETT, W. C.; CHANTON, J. P.; CORBETTA, J. E. Application of radon-222 to investigate groundwater discharge into small shallow lakes. Journal of Hydrology, v. 486, p. 112-122, 2013.

DRUMOND, M. M. A técnica de traçadores e o seu potencial para ampliar o conhecimento hidrológico sobre as bacias brasileiras: um estudo aplicado a bacia representativa de Juatuba - MG. Belo Horizonte, MG, 2004. 199 p. Tese (Doutorado em Saneamento, Meio Ambiente e Recursos Hídricos). Universidade Federal de Minas Gerais.

DUGAN, H.A.; GLEESON, T.; LAMOUREUX, S.F.; NOVAKOWSKI, K. Tracing groundwater discharge in a high Arctic lake using radon-222. Environment Earth Science, v. 66, n. 5, p. 1385-1392, 2012.
DURRIGDE RADON INSTRUMENTATION. RAD7 Radon Manual. Durridge Company. Revision 7.3.2, 2015.

ERŐSS, A.; MÁDL-SZŐNYIA, J.; SURBECK, H.; HORVÁTH, A.; GOLDSCHEIDER, N.; CSOMA, A. E. Radionuclides as natural tracers for the characterization of fluids in regional discharge areas, Buda Thermal Karst, Hungary. Journal of Hydrology, v. 426-427, p. 124-137, 2012.

FERREIRA, V.V.M.; FONSECA, R.L.M.; ROCHA, Z.; OLIVEIRA, A.L.; MOREIRA, R.M.; LEMOS, N.C.; CHAGAS, C.J.; MENEZES, M.A.B.C.; SANTOS, T.O. Use of Radon as Water Tracer at Juatuba Basin. Journal of Geography and Geology, v. 7, n.3, p. 49-60, 2015.

GOLDSCHEIDER, N.; MEIMAN, J.; PRONK, M.; SMART, C. Tracer tests in karst hydrogeology and speleology. International Journal of Speleology, v. 37, n. 1, p. 27-40, 2008.

SANTOS, I. R.; EYRE, B. D. Radon tracing of groundwater discharge into an Australian estuary surrounded by coastal acid sulphate soils. Journal of Hydrology, v. 396, n. 3-4, p. 246-257, 2011.

SAVOY, L.; SURBECK, H.; HUNKELER D. Radon and $\mathrm{CO}_{2}$ as natural tracers to investigate the recharge dynamics of karst aquifers. Journal of Hydrology, v. 406, n. 3-4, p. 148-157, 2011.

SCHUBERT, M.; PASCHKE, A. Radon, $\mathrm{CO}_{2}$ and $\mathrm{CH}_{4}$ as environmental tracers in groundwater/surface water interaction studies - comparative theoretical evaluation of the gas specific water/air phase transfer kinetics. The European Physical Journal, v. 224, p. 709-715, 2015. 